\title{
EFEITO DO ANELAMENTO E DO ÁCIDO GIBERÉLICO NA FRUTIFICAÇÃO DA UVA SEM SEMENTES 'MARIA'
}

\section{GEOVANITA PAULINO DA COSTA KALIL \\ Engenheiro Agrônomo}

Orientador: Dr. MAURILO MONTEIRO TERRA

Dissertação apresentada à Escola Superior de Agricultura "Luiz de Queiroz", Universidade de São Paulo, para obtenção do título de Mestre em Agronomia, Área de Concentração: Fitotecnia

\author{
$P \mid R A C I C A B A$ \\ Estado de São Paulo - Brasil \\ Janeiro - 1998
}


Kalil, Geovanita Paulino da Costa

Efeito do anelamento e do ácido giberélico na frutificação da uva sem sementes 'Maria' / Geovanita Paulino da Costa Kalil - - Piracicaba, 1998.

$55 \mathrm{p}$.

Dissertação (mestrado) - - Escola Superior de Agricultura "Luiz de Queiroz", 1998. Bibliografia.

1.Ácido giberélico 2. Anelagem 3. Frutificação 4. Prática cultural 5. Uva I. Titulo 


\section{EFEITO DO ANELAMENTO E DO ÁCIDO GIBERÉLICO NA FRUTIFICAÇÃO DA UVA SEM SEMENTES 'MARIA'}

\section{GEOVANITA PAULINO DA COSTA KALIL}

Aprovada em: 30.03 .1998

Comissão julgadora:

Prof. Dr. João Alexio Scarpare Filho ESALQ/USP

Dr. Maurilo Monteiro Terra IAC Dr. Erasmo José Paioli Pires

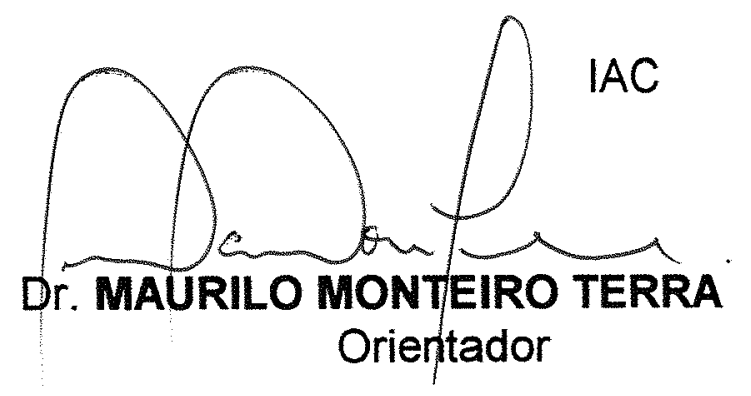




\section{HONRA GLORIA LOUVOR}

Ao Deus autor da minha vida

A Jesus Cristo, meu Salvador

Ao Espirito Santo, meu Consolador.

"Ainda que eu ande pelo vale da sombra da morte não temerei mal nenhum, porque tu estás comigo: a tua vara e o teu cajado me consolam".

Salmo 23:4 
Às minhas mães e avó

Aparecida e Rosa

Ao meu marido Kalil

Aos meus filhos Raquel e

Gabriel

DEDICO 


\section{AGRADECIMENTOS}

A DEUS autor da vida, que está sobre o controle de todas a coisas na minha vida em primeiro lugar.

Ao Dr. Maurilo Monteiro Terra, pela orientação, amparo e incentivo durante a execução deste trabalho.

Aos professores, funcionários e alunos da Escola Superior de Agricultura "Luiz de Queiroz", mormente do Departamento de Agricultura e Horticultura, pelos ensinamentos transmitidos durante as disciplinas que tomaram parte de minha formação profissional, apoio e coleguismo.

Ao Instituto Agronômico de Campinas (IAC) pela cessão de funcionários, equipamentos e instalações para a realização deste trabalho.

Ao Conselho Nacional de Desenvolvimento Científico e Tecnológico (CNPq), pela concessão de Bolsa de Pós-Graduação, que possibilitou-me a realização do Curso de Pós-Graduação.

Ao Srs. José Roberto e Nilo Carbonari, da Chácara Extra-Vitis, município de Jundiaí pela cessão do vinhedo para a instalação do experimento.

À Sra. Meire Correia da Silva Ferrari, funcionária do Instituto Agronômico de Campinas (IAC), pelo apoio para a realização das medidas de laboratório.

Ao pesquisador da EMBRAPA Jefferson Luiz Vasconcelos de Macedo, pelo apoio para a realização das análises estatísticas.

Ao meu querido marido Antonio Nascim Kalil Filho, pelo apoio e colaboração em fases do trabalho. 


\section{SUMÁRIO}

Página

LISTA DE FIGURAS .................................................................. iv

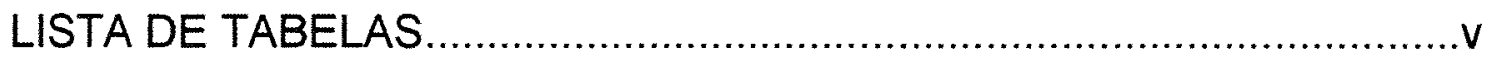

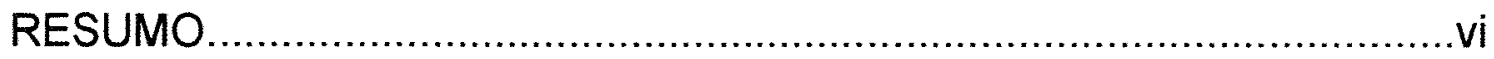

SUMMARY ........................................................................................

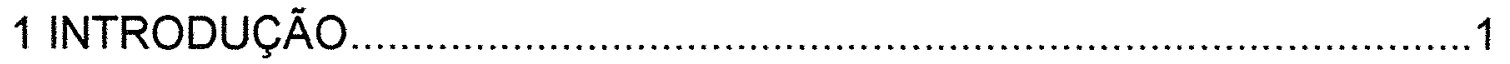

2 REVISÃO DE LITERATURA ....................................................

2.1 Anelamento na cultura da videira: conceito e finalidade......................3

2.2 Efeito do anelamento em cultivares de uva de mesa........................5

2.3 Anelamento químico.................................................................

2.4 Modificações fisiológicas na planta com o anelamento.......................8

2.5 Aplicação do Ácido giberélico $\left(\mathrm{GA}_{3}\right)$ : conceito e finalidade .................8

2.6 Efeito do ácido giberélico em cultivares de uva de mesa...................9

2.7 Modificações citológicas e fisiológicas na planta com a aplicação do

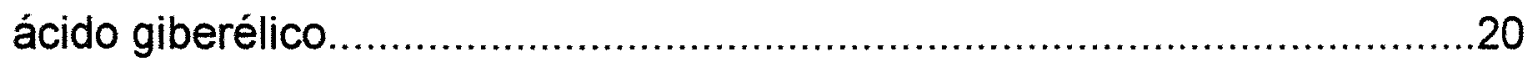

2.8 Efeito do anelamento associado ao ácido giberélico em cultivares de

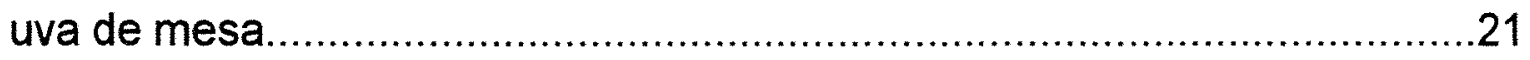

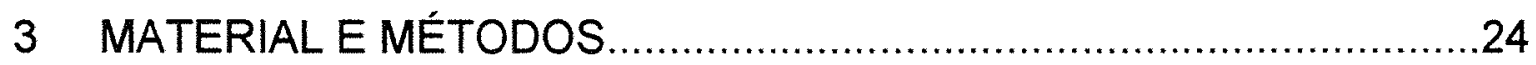

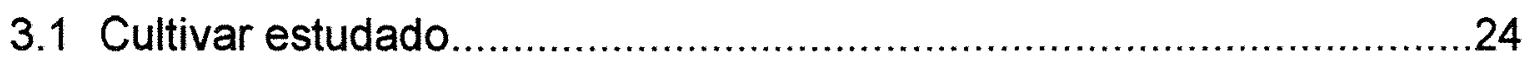

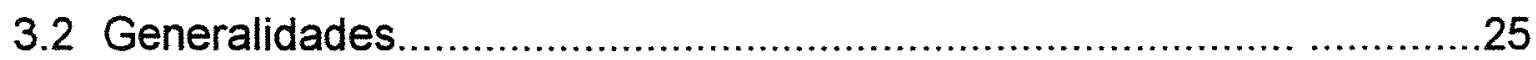

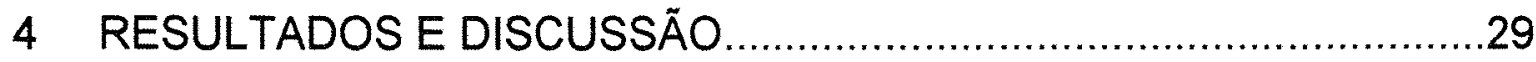

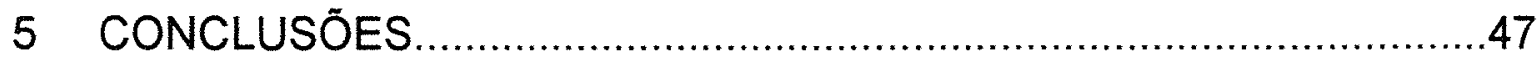

REFERÊNCIAS BIBLIOGRÁFICAS ..........................................48 


\section{LISTA DE FIGURAS}

Página

1 Efeito do anelamento e aplicação de ácido giberélico sobre o peso de bagos de uva cultivar Maria.

2 Efeito do anelamento e aplicação de ácido giberélico sobre o comprimento de bagos de uva cultivar Maria.

3 Efeito do anelamento e aplicação de ácido giberélico sobre a largura de bagos de uva cultivar Maria.

4 Efeito do anelamento e aplicação de ácido giberélico sobre o diâmetro do pedicelo de uva cultivar Maria.

5 Efeito do anelamento e aplicação de ácido giberélico sobre o número total de bagos de uva cultivar Maria.

6 Efeito do anelamento e aplicação de ácido giberélico sobre o peso de 30 bagos de uva cultivar Maria.

7 Efeito do anelamento e aplicação de ácido giberélico sobre o peso de cachos de uva cultivar Maria.

8 Efeito do anelamento e aplicação de ácido giberélico sobre o comprimento de cachos de uva cultivar Maria.

9 Efeito do anelamento e aplicação de ácido giberélico sobre a largura de cachos de uva cultivar Maria.

10 Efeito do anelamento e aplicação de ácido giberélico sobre o peso de engaços de uva cultivar Maria. 36

11 Efeito do anelamento e aplicação de ácido giberélico sobre o comprimento de engaços uva cultivar Maria.

12 Efeito do anelamento e aplicação de ácido giberélico sobre a largura de engaços de uva cultivar Maria. 


\section{LISTA DE TABELAS}

Página

1 Médias dos tratamentos com anelamento e/ou ácido giberélico no tronco ou nos ramos efetuados no início ou após o florescimento da cultivar de uva de mesa Maria.

2 Efeito da época do anelamento e/ou época de aplicação do ácido giberélico $\left(\mathrm{GA}_{3}\right)$ nas características das bagos, dos cachos e dos engaços de uva de mesa Maria

3 Valores das médias dos tratamentos que compõem os contrastes ortogonais para diferentes características das bagos, cachos e engaços de uva de mesa cultivar Maria.

4 Análises de variância dos contrastes ortogonais entre médias das características das bagos, cachos e engaços de uva de mesa cultivar Maria. .34

5 Incrementos médios percentuais entre os contrastes de médias para as características de bagos, cachos e engaços de uva de mesa 'Maria' 


\title{
EFEITO DO ANELAMENTO E DO ÁCIDO GIBERÉLICO NA FRUTIFICAÇÃO DA UVA SEM SEMENTES 'MARIA'
}

\author{
Autora: GEOVANITA PAULINO DA COSTA KALIL \\ Orientador: Dr. MAURILO MONTEIRO TERRA
}

\section{RESUMO}

Este trabalho foi desenvolvido com o objetivo de avaliar a resposta do cultivar Maria (IAC 514-6) ao anelamento e à aplicação de ácido giberélico na concentração de 200ppm, no início ou após o florescimento, para as características dos cachos, bagos e engaços. O experimento foi realizado em Jundiaí, SP, e o delineamento estatístico foi inteiramente casualizado, com doze tratamentos e cinco repetições. Não foram detectados efeitos de época de anelamento ou de aplicação de ácido giberélico. Efeitos significativos do anelamento no tronco ou nos ramos e da aplicação do ácido giberélico ou de ambos os tratamentos foram detectados para as características estudadas. Os incrementos verificados para essas características foram semelhantes ao serem aplicados os fatores isoladamente ou em conjunto. 


\section{EFFECT OF GIRDLING AND GIBBERELLIC ACID ON THE FRUTIFICATION OF 'MARIA' SEEDLESS GRAPEVINE}

Author: GEOVANITA PAULINO DA COSTA KALIL Adviser: Dr. MAURILO MONTEIRO TERRA

\section{SUMMARY}

This work was developed with the aim of evaluate the response of grapevine cultivar Maria (IAC 514-6) to branches and trunk girdling at the beginning or after flowering associated or not to gibberelic acid (200 ppm) for clusters, berries and raquis characteristics. The experiment was performe at Jundiaí, São Paulo State, Brazil. It was installed in a randomized complete design, with 12 treatments and 5 replications. No effect of girdling time nor $\mathrm{GA}_{3}$ application were detected. Significative effects of trunk or branches girdling and $\mathrm{GA}_{3}$ application or from both treatments together for all the characteristics of the berries, clusters and raquis were detected. The application of each treatment alone or in combination influenced the grape traits in a similar manner. 


\section{INTRODUÇĀO}

O mercado consumido: internacional de uva de mesa tem preferência pelos cultivares sem sementes. Entretanto, estes requerem práticas culturais como anelamento e aplicação de reguladores de crescimento, que influenciam no tamanho e no desenvolvimento da cor dos bagos, na antecipação da maturação, afetando, ainda, a compacidade e o pegamento dos frutos (Weaver, 1976).

$O$ anelamento ou incisão anelar, prática usual na viticultura em outros países, é incomum no Brasil. Consiste na remoção de um anel de casca do tronco ou de ramos lenhosos de 3 a $6 \mathrm{~mm}$ de largura. Como consequêencia, ocorre acúmulo de carboidratos acima da incisão, quando a casca é completamente removida (Pommer et al., 1991). O anelamento influencia diretamente $O$ desenvolvimento da inflorescência e frutificação (Le Clerc du Sablon, 1905; Murneek, 1941 e Winkler et al., 1974). Conseqüentemente, os bagos têm seu tamanho aumentado em cultivares sem sementes, podendo, ainda, ocorrer a antecipação da maturação, aumento no número de bagos e no pegamento, de cultivares que possuem cachos ralos durante ou imediatamente após o florescimento (Winkler et al., 1974). 
A ação da giberelina vem sido intensivamente estudada em viticultura. Aplicações efetuadas desde 0 aparecimento da inflorescência até o início da maturação visam principalmente ao aumento da produção através do aumento do peso dos cachos e dos bagos e à obtenção de cachos medianamente soltos (que dispensam a operação de desbaste e facilitam o controle de doenças). Além disso, a aplicação do ácido giberélico - $\mathrm{GA}_{3}$ pode acarretar no engrossamento dos pedicelos e engaços e obtenção de frutos sem sementes, com diminuição do ciclo da videira, antecipando-se o periodo de colheita (Pereira \& Oliveira, 1976).

Este trabalho foi desenvolvido com o objetivo de avaliar a resposta do cultivar de uva de mesa sem sementes Maria (IAC 514-6) ao anelamento e à aplicação de ácido giberélico, no início ou após o florescimento, para as características dos cachos, engaços e bagos. 


\section{REVISĀO DE LITERATURA}

A boa aparência e o tamanho dos cachos e dos bagos das uvas de mesa representam características essenciais integrantes da preferência dos consumidores. O mercado consumidor internacional de uva de mesa tem preferência pelos cultivares sem sementes, característica fundamental buscada nos programas de melhoramento genético.

O cultivo de uvas sem sementes, segundo Pires et al.(1987) tem despertado o interesse de produtores e vem se expandindo no Estado de São Paulo, após o lançamento de vários cultivares pelo Instituto Agronômico de Campinas. O mercado consumidor, por sua vez, tem demonstrado grande aceitação por este produto.

\subsection{Anelamento na cultura da videira: conceito e finalidade}

O anelamento ou incisão anelar é a remoção total de um anel de casca, de largura variável, de 3 a $6 \mathrm{~mm}$ no tronco, no cordão esporonado, ou no ramo produtivo próximo ao cacho (Pommer ef al., 1991). 
Diversos cultivares de uvas de mesa sem sementes são propensos a defeitos de qualidade, tais como bagos pequenos, desuniformes e abscisão de bagos, que acarretam perdas na produção (Wolf et al, 1994).

Jacob (1931) recomendou o anelamento do tronco ou dos ramos, do cV. Thompson Seedless para aumentar o tamanho dos bagos. Sugeriu, para maior eficiência do anelamento, que este deveria ser feito quando os bagos tivessem alcançado cerca de $1 / 4$ de seu crescimento total. Ressaltou, entretanto, o risco de enfraquecimento das plantas. Nesse caso, é fundamental o bom estado nutricional e o adequado fornecimento de água ao parreiral para permitir o anelamento por diversos anos.

O anelamento tem sido utilizado extensivamente para aumentar a produção em videira, mas seu uso comercial tem sido mais comum em uvas sem sementes que em uvas com sementes Weaver et al., 1962; Winkler et al., 1974).

O estádio no qual se pratica o anelamento é o principal fator determinante do efeito a ser obtido. Winkler et al. (1974) destacou três finalidades para o anelamento: 1) melhorar o pagamento dos bagos de certos cultivares que possuem cachos ralos, durante ou imediatamente após o florescimento; 2) aumentar o tamanho dos bagos de variedades sem sementes devendo ser feito durante ou imediatamente após a queda natural das flores inférteis e até que os bagos tenham tamanho "chumbinho"; 3) apressar a maturação de uvas com sementes e/ou melhorar a cor de seus bagos, devendo ser feito quando os bagos começam a mudar de cor e/ou amolecer. 


\subsection{Efeito do anelamento em cultivares de uva de mesa}

Os primeiros trabalhos registrados na literatura sobre anelamento datam do princípio deste século. Fisher (1905) observou que o anelamento apressa e aumenta o florescimento.

Winkler (1953) desenvolveu experimento sobre o efeito do tempo de anelamento em cv. Thompson Seedless, visando o aumento do tamanho de bagos. Verificou que para obter o máximo incremento no tamanho de bagos, o anelamento deve ocorrer imediatamente após a queda de flores inviáveis, seguido de florescimento que coincide com o tempo de mais rápido desenvolvimento de bagos. Considerável aumento no desenvolvimento de bagos comparado a videiras não aneladas ocorreu quando o anelamento foi atrasado em 6 dias, mas $o$ peso de bagos quase não aumentou quando 0 anelamento fol atrasado em 3 semanas.

Weaver (1955) realizou experimentos com anelamento nos cultivares Málaga e Ribier de 1952 a 1954 em Davis, Califórnia. Verificou que anelamento precoce apressa a maturação, talvez porque 0 anelamento nessa fase do desenvolvimento coincida com redução da atividade vegetativa. $O$ anelamento efetuado no $3^{\circ}$ experimento apressou mais a maturação que os anelamentos dos dois primeiros experimentos (1952 e 1953), talvez devido à diferenças nas condições climáticas entre os anos. Outros autores comentam que, possivelmente devido a esses fatores climáticos, o anelamento é eficiente no sentido de apressar a maturação por um longo período em determinados anos, mas que em outros casos, a eficiência do anelamento ocorre por um curto periodo. Dentre estes fatores climáticos intervenientes na maturação dos frutos, são apontados o número de dias quentes (deve 
haver um número mínimo de dias quentes para $\circ$ crescimento vegetativo do tronco e das brotações da videira).

Em cultivares com sementes, usualmente bagos sem sementes entram em abscisão e caem. O anelamento, além de permitir a retenção de bagos sem sementes, aumenta o número de bagos com sementes, (Coombe, 1959). Troncos do cultivar Thompson Seedless foram anelados na época do florescimento e após a formação dos frutos para reduzir o número e aumentar o tamanho de bagos (Weaver, 1955). Este autor mostrou que, em regiōes onde a colheita deve ser apressada, ou por aproximação do inverno - EUA, o anelamento precoce (quando o teor de sólidos solúveis é de 5-60Brix) deve ser tentado.

Produtividade excessiva poderia acarretar aumento mínimo no peso de bagos resultante do anelamento (Winkler, 1953). A redução na concentração de sólidos solúveis, mesmo usando-se o anelamento e - $G A_{3}$, também pode ser atribuida ao excesso de produção da videira (Jacob, 1931; Weaver \& Mc Cune, 1959, Weaver \& Mc Cune, 1959a; Andris, 1981).

Pommer et al. (1991) verificaram que o anelamento nos cultivares Traviú e Niagara Rosada não influenciou nenhuma das características avaliadas (peso, comprimento e largura dos cachos, peso de 50 bagos, teor de sólidos solúveis totais e acidez total do suco), sendo as médias bastante semelhantes às das plantas não aneladas.

Em Santa Catarina, Peruzzo (1994), verificou que o anelamento permite antecipar a maturação, podendo ainda promover a uniformização do tamanho dos frutos, com melhoria da aparência final dos cachos. Este autor verificou, ao trabalhar com os cultivares Cardinal e Ruby Seedless, que o anelamento provocou o adiantamento da maturação, em média, de doze dias para os ramos anelados na 
floração e de sete dias para aqueles anelados no início da maturação. O cultivar Cardinal apresentou ganhos de peso médio dos cachos em $21 \%$ e $9 \%$ nos ramos anelados na floração e início da maturação. respectivamente. No cultivar Ruby Seedless, os aumentos no peso dos cachos foram de $29 \%$ e $12 \%$, respectivamente na floração e início da frutificação. Para ambos os cultivares, os resultados demonstraram ser vantajoso o anelamento na floração. Contudo, o autor comenta que a decisão pelo anelamento é dependente da relação dos custos da operação com os preços das uvas no mercado.

\subsection{Anelamento químico}

Morfatinas são inibidores sintéticos de crescimento (Newman et al., 1977). Videiras são tratadas com morfatina mais óleo emulsionável. A solução de morfatina é aplicada com um pincel no tronco em faixa que varia de 15 a $30 \mathrm{~cm}$. Pedaços de casca solta são removidos antes da aplicação. Este tratamento associado ao anelamento é conhecido como anelamento químico ("chemical girdling") (Shulman et al., 1986). O efeito do anelamento químico é acentuado em relação ao anelamento comum devido à redução da acidez. A falta de resposta, algumas vezes, é atribuida às práticas culturais ou a práticas de manejo. Tratamentos com morfatina nas concentrações de 300 e $600 \mathrm{mg} / \mathrm{l}$ em plantas do cultivar Thompson Seedless aumentaram o tamanho dos bagos, reduzindo a acidez. 


\subsection{Modificações fisiológicas na planta com o anelamento}

Diversas investigações mostraram que o anelamento aumenta o acúmulo de substâncias de reserva acima da região anelada, influenciando diretamente $\circ$ desenvolvimento da inflorescência e a frutificação (Le Clerc Du Sablon, 1905; Murneek, 1941; Winkler et al. 1974) e que ele está relacionado com maior formação de inflorescências.

O aumento do tamanho dos bagos em videiras aneladas pode ser explicado por aumentar o nível de carboidratos (Weaver \& Mc. Cune, 1959; Kriedemann \& Lenz, 1972), alterações nos niveis hormonais ou a combinação de ambos os fatores acima da região anelada (Weaver \& Mc Cune, 1959; Weaver et al., 1969; Kriedemann \& Lenz., 1972; Adams et al, 1975).

\subsection{Aplicação do ácido giberélico ( $\left(\mathrm{A}_{3}\right)$ : conceito e finalidade}

A importância do ácido giberélico no desenvolvimento das características agronômicas tem sido demonstrada em muitas espécies frutiferas sendo que aplicações comerciais deste produto químico têm sido realizadas, particularmente na videira, onde é de grande importância econômica, especialmente em cultivares desprovidos de sementes (Winkler \& Williams, 1963).

Coombe (1960) efetuou determinações no crescimento e desenvolvimento de certas partes do fruto e sementes de dois cultivares com sementes e três sem sementes de Vitis vinifera, da antese à maturação. Os frutos de todos os cultivares mostraram uma curva de 
crescimento. Nos dois cultivares com sementes, o primeiro ciclo de crescimento foi paralelo pela ascensão e queda da atividade meristemática nas sementes e pelo conteúdo de auxina nos bagos. Isto pode ser explicado pela descoberta da atividade de giberelina em bagos novos de três cultivares apirenos. Não fol encontrada atividade de giberelina em bagos com sementes em nenhuma ocasião. Este fato de que cultivares sem sementes aumentam consideravelmente em tamanho após tratamento com giberelina, auxina e anelamento, enquanto que cultivares com sementes não o fazem, sugerem que as giberelinas são GA3s importantes no fruto dos cultivares sem sementes.

A aplicação do ácido giberélico associada ou não ao anelamento constituem-se em tratamentos utilizados para aumentar 0 tamanho dos bagos e reduzir o número de bagos em cultivares de uvas sem sementes, com a conseqüente melhoria da qualidade do produto para o mercado. Os diversos trabalhos conduzidos no Brasil e no exterior sobre estes efeitos têm apresentado respostas diferenciais a estes tratamentos. Pires et al.(1987) destacam que as diferenças nas respostas destes agentes é dependente principalmente do cultivar e das condições climáticas, determinando, assim, a necessidade de novas pesquisas no sentido de se descobrir a concentração adequada de $\mathrm{GA}_{3}$ e as melhores épocas de aplicação.

\subsection{Efeito do ácido giberélico em cultivares de uva de mesa}

Stewart et al. (1957), verificaram aumento apreciável no comprimento dos bagos (50\% maiores que o controle), após aplicações de ácido giberélico nas concentrações de 10ppm ou 100ppm sobre 
cachos da 'Thompson Seedless' e 'Perlette' durante a floração. Os mesmos cultivares apresentaram grande percentagem de bagos pouco desenvolvidos por cacho quando foram pulverizados com giberelina a 100ppm por quatro semanas consecutivas após o florescimento.

Pratt \& Schaulis (1961) aplicaram $\mathrm{GA}_{3}$ em uvas com sementes e obtiveram uma alta porcentagem de uvas sem sementes, especialmente sob condições de polinização reduzida ou inibida. Em muitos outros casos, entretanto, o $G A_{3}$ falhou em induzir a formação de frutos partenocárpicos (Motomura \& Hori, 1978), o que aponta para 0 fato de que os cultivares devem ser avaliados individualmente para estc característica.

Hidalgo \& Candela (1965) pulverizaram bagos dos cultivares Frankental e Sultanina, na fase de chumbinho, obtendo aumento no peso dos cachos e dos bagos, engrossamento dos pedicelos, diminuição do peso médio de sementes por bago do cultivar Frankental, aumento nos teores de açúcar e adiantamento da maturação. Em aplicações múltiplas, obtiveram resultados semelhantes com os cultivares Rosaki, Garnacha e Sultanina.

Weaver \& Olmo (1957) efetuaram aplicações de giberelinas em estádios anteriores ao florescimento em cultivares européias de uva, constatando antecipação do florescimento, assim como alongamento de partes do cacho, incluindo o pedúnculo, pedicelo e engaço.

Pereira (1972) verificou em 'Niagara Rosada', que a aplicação de giberelina por imersão na inflorescência, provoca 0 aumento de tamanho dos cachos, além de rápido aumento no tamanho das inflorescências, promovendo adiantamento da floração e maturação. 
Jindal et al. (1975), estudaram o efeito de várias concentrações de ácido giberélico aplicado em diversos estádios de desenvolvimento de inflorescência de videira 'Thompson Seedless'. GA3 a 20,40 ou 60ppm foi pulverizado nos rácemos nos estádios de floração a saber: 25,50 ou $75 \%$ de flores abertas ou em pós-floração. Pulverizando-se particularmente 40 ppm após a floração em qualquer dose resultou em redução do número de bagos por cacho. Bagos graúdos, com maior relação comprimento/largura, foram obtidos com aplicação de giberelina a 40 ou 60 ppm após o florescimento.

Barcellos (1976), Guerra et al. (1981), Penteado et al. (1975) e Pereira \& Oliveira (1976) aplicaram ácido giberélico em concentrações de 2,5 a 40 ppm no período compreendido entre a préfloração e a queda natural dos frutos. O crescimento dos cachos e o desenvolvimento de suas partes estruturais aumentaram os bagos tornando-se mais uniformes. Também foram obtidos a antecipação do período de maturação, o aumento no teor de sólidos solúveis totais e a diminuição da acidez total. Guerra et al. (1981) observaram a formação de bagos sem sementes como resultado da ação do ácido giberélico sobre os cachos do cultivar Itália.

Sharma et al. (1975) imergiram em soluções aquosas de ácido giberélico a 25 ou 50 ppm, rácemos de videira Perlette nos estádios de plena floração ou queda de bagos. Concluíram que os tratamentos aumentaram $o$ peso dos cachos $e$ dos bagos $e$ melhoraram a qualidade do fruto, particularmente na dose maior.

Pereira \& Oliveira (1976), ao estudar os efeitos do ácido giberélico sobre cachos do cultivar de uva Patricia, concluíram que: 1) a aplicação do ácido giberélico em dose de 20ppm no início da frutificação permitiu maior desenvolvimento no comprimento e peso dos 
cachos. À exceção do tratamento 5ppm, o ácido giberélico aumentou significativamente 0 peso dos bagos em comparação com a testemunha. Em relação ao aspecto do cacho, a aplicação do ácido giberélico permitiu a formação de cachos relativamente soltos, bagos graúdos, de valor comercial superior à testemunha em todos os tratamentos onde se fez a aplicação no início da frutificação. A análise conjunta das variáveis estudadas no presente ensaio mostrou serem os tratamentos com giberelina efetuados no início da frutificação, aqueles que trouxeram resultados mais vantajosos aos cachos de Patrícia, sendo que a menor dose foi a mais eficiente.

Pereira \& Oliveira (1976) avaliaram o efeito da giberelina em diferentes doses e épocas sobre a uva cv. Patrícia e concluíram que a aplicação de giberelina (5ppm) no periodo anterior ao florescimento não eliminou a necessidade de desbaste manual e provocou a retenção de bagos inviáveis, dificultando esta operação. As aplicações de giberelina (5 e 10ppm) durante o inicio da frutificação, propiciaram a formação de cachos e bagos mais pesados. Os teores de sólidos solúveis totais, o aspecto e a necessidade de desbaste manual não foram afetados por estas aplicações.

Sarooshi (1977) estudou os efeitos da giberelina no cultivar de videira Sultana, clone $H_{1}$, quanto às características de tamanho da baga, produtividade, resistência ao transporte, características de cacho e engaço. Verificou que com 3 pulverizações de $\mathrm{GA}_{3}$ na dose de 160 ppm em diferentes fases do desenvolvimento, permitiram a produção de cachos com bagos graúdos, pesando mais de 5 gramas cada. Contudo, este tratamento atrasou a maturação dos frutos e produziu muitos cachos compactos. Similar tamanho de bagos, sem retardar a maturação e cachos medianamente soltos, foram obtidos reduzindo 0 
ácido giberélico a duas aplicações, a primeira à dose de 10ppm quando os rácemos apresentavam $50 \%$ de flores abertas, e a segunda quando as bagos apresentavam $3-4 \mathrm{~mm}$ de diâmetro. Os tratamentos não afetaram significativamente o tamanho dos engaços.

Ruby Seedless, também chamado King's Ruby é um cultivar de uva de mesa sem sementes, que apresenta cachos compactos. $O$ 'Ruby Seedless' é sensivel ao $\mathrm{GA}_{3}$ a 1ppm (redução do número de bagos e bagos maiores), enquanto que a dose de $2,5 \mathrm{ppm}$ resulta na formação de bagos pequenos nas condições climáticas da Califórnia (Makivios, 1977).

Aplicações únicas de giberelina no cultivar Ruby Seedless em concentrações de 2,5, 5 ou 10ppm em pré ou plena floração (até $60 \%$ de caliptras caídas) provocaram má formação dos cachos devido á alta ocorrência de bagos tipo "chumbinho". Entretanto, quando o ácido giberélico é aplicado na dose de lppm no final da floração provoca um favorável índice de descompactação, sem alterar o peso e o teor de sólidos solúveis dos bagos (Jensen et al., 1976).

Kasimatis ef al, (1978) verificaram que aplicacões de giberelina nas concentrações de 5 a 10ppm, em condições de plena floração, promoveram pequeno aumento no peso dos bagos da videira 'Thompson Seedless'. Verificaram ainda que o referido regulador de crescimento quando aplicado nestas condições não afetou 0 rendimento por planta, nem aumentou o teor de açúcar quando a fruta foi industrializada.

Singh et al. (1978) constataram para o cultivar Thompson Seedless a ocorrência de máximo aumento no peso dos bagos com uma aplicação de $15 \mathrm{ppm}$ de $\mathrm{GA}_{3}$ no florescimento seguida de três 
aplicações de 40ppm, no início da frutificação, duas e quatro semanas após.

Um dos efeitos do $G A_{3}$ está em induzir a formação de frutos partenocárpicos em alguns cultivares de uvas (Motomura \& Ito, 1972; Motomura \& Hori, 1978).

El-Banna \& Weaver (1979) estudaram o efeito da giberelina no cultivar Thompson Seedless, efetuando aplicação única uma semana após a floração em 3 doses: 5, 25 e 50ppm. Verificaram que o peso do cacho, a compacidade, o peso por bago e o volume por bago aumentaram significativamente à medida em que foram aumentadas as doses.

Baron et al. (1981) concluíram que dupla aplicação de $\mathrm{GA}_{3}$ nas doses de 7, 10 e 15ppm, em condições de floração e 20, 30 e 40ppm após a floração, propiciaram aumento efetivo no tamanho da baga dos cultivares Esmerald Seedless, Flame Seedless e Ruby Seedless, entretanto, somente os dois primeiros cultivares apresentaram cachos descompactados.

No Chile, o cultivar de uva Moscatel Rosada representa alternativa para exportação. Entretanto, existem problemas para a obtenção de cachos com bagos de tamanhos uniformes. $O$ desbaste do terço inferior dos cachos e a aplicação de $\mathrm{GA}_{3}$ são práticas visando a correção destes problemas (Lavin, 1982).

Ezzahouani et al. (1985), em experimento conduzido na Califórnia com os cultivares Thompson Seedless e Ruby Seedless, obtiveram para o cultivar Thompson Seedless cachos maiores pela associação do $\mathrm{GA}_{3}$ a 40ppm e anelamento no início da frutificação. Nem o teor de sólidos solúveis, nem a acidez foram afetados significativamente pelos tratamentos. Os resultados com o cultivar Ruby 
Seedless foram os seguintes: não foram detectadas diferenças significativas para produção e peso dos cachos com aplicações de $\mathrm{GA}_{3}$ e anelamento. Contudo, houve tendência na redução nas produções com $\circ$ aumento das concentrações de $\mathrm{GA}_{3}$ no florescimento. $O$ peso de bagos não aumentou com os tratamentos. $A$ uva 'Ruby Seedless' apresentou respostas significativas quanto ao número de bagos por cacho e altamente significativo para número de bagos/cm, o qual é considerado um bom indicador de compactação do cacho.

Lavin (1982) realizou ensaio com desbaste de cachos, combinados ou não com aplicação de $\mathrm{GA}_{3}$ no cultivar de uva Moscatel Rosada. A aplicação de $G A_{3}$, independente do desbaste de cachos acarretou em aumento do peso dos cachos. Ocorreu aumento no número de bagos, cujos pesos diminuíram com aplicação de $\mathrm{GA}_{3}$.

Pires et al. (1987) estudaram a influência de doses e épocas de aplicações do ácido giberélico sobre as características morfológicas do cacho da videira IAC 457-11 'Iracema'. As aplicações foram feitas em pré-florescimento, durante o florescimento e após o florescimento. Em termos gerais, não houve diferenças significativas entre doses de $G A_{3}$ utilizadas nas diferentes épocas de aplicação para as variáveis analisadas.

Pires (1988) aplicou três doses de $G A_{3}$ em três épocas diferentes do ciclo da uva 'Maria' e concluiu que os melhores tratamentos encontrados consistiram na aplicação de $G A_{3}$ nas doses de 400 ou 800 ppm, 14 dias após a floração, ocorrendo grande aumento no peso dos cachos e dos bagos, sem aumentar excessivamente o número de bagos "chumbinho" por cacho. Houve também melhoria na 
morfologia da baga, proporcionando cachos com características adequadas para o mercado consumidor.

A aceitabilidade de mercado da uva sem sementes 'Orlando' é limitada pelo seu pequeno tamanho de bagos e a presença ocasional de traços de sementes. Em experimentos com três anos de idade deste cultivar (Halbrooks \& Crovetti, 1989), pulverizações de $\mathrm{GA}_{3}(10 \mathrm{mg} / \mathrm{l})$ não mostraram efeito, mas na dose de $40 \mathrm{mg} / \mathrm{l}$ após o florescimento, aumentaram o tamanho de bagos, havendo redução no peso e número (freqüência) de traços de sementes, comparados com os controles não tratados. Esta dose, entretanto, não apresentou efeitos de incremento no peso de bagos em relação à aplicação de $30 \mathrm{mg} / \mathrm{l}$ de $G A_{3}$ após o florescimento, mas os traços de sementes foram reduzidos.

Ben-Tal (1990) realizou 20 ensaios de aplicação de $\mathrm{GA}_{3} \mathrm{com}$ o cultivar Thompson Seedless em áreas de produtores em Israel.. Constatou que o peso médio dos bagos aumentou com o número de aplicações de $\mathrm{GA}_{3}$ até quatro aplicações, não ocorrendo aumentos significativos no peso de bagos após quatro aplicacões. À medida que - número de aplicações aumentou, o conteúdo de sólidos solúveis diminuiu e a acidez aumentou, o que são indícios de retardamento da maturação dos bagos. A queda de bagos aumentou com o aumento do número de aplicações, chegando à queda de $20 \%$ dos bagos com seis aplicações.

Cultivares de uva de mesa sem sementes plantados na África do Sul, como Muscat Seedless, Flame Seedless e Sultanina apresentam defeitos de qualidade, como desuniformidade no tamanho e abscisão ou queda de bagos, os quais causam as maiores perdas na produção (Wolf et al., 1994), requerendo, desta forma, experimentação 
intensa. Oth (1990) efetuou pulverizações com ácido giberélico em diversas concentrações nos cachos de videiras, em diversas épocas de aplicação. Verificou o retardamento no aparecimento das inflorescências, dos frutos tipo "chumbinho" e dos frutos pequenos, o que acarretou a redução do peso médio dos cachos. A imersão das inflorescências em ácido giberélico não causou atraso no aparecimento dos frutos tipo "chumbinho", nem no número de inflorescências, tamanho dos frutos e peso dos cachos.

Orth (1990a) tratou folhas apicais, inflorescências, frutos tipo "chumbinho" e ramos da uva 'Muscat Seedless' com $\mathrm{GA}_{3}$ a 10ppm, quando 0, 33, 66 ou 100\% das caliptras haviam caido. O número de bagos e cachos foi menor quando a imersão em $G A_{3}$ ocorreu antes do início da queda das caliptras. Embora tenha aumentado o número de bagos com a imersão tardia, ainda este número foi menor que os controles, demonstrando que a aplicação de $\mathrm{GA}_{3}$, em qualquer época do florescimento, acarretou na redução do número de bagos. Os tratamentos mais precoces permitiram a formação de bagos mais elongados e os tratamentos tardios, bagos mais arredondados. $O$ número de ovários de bagos retidos pelos cachos até a colheita fol excessivamente alto em todos os tratamentos por imersão, evidenciando que o ácido giberélico na dose de 10ppm é um tratamento não recomendado como agente de redução do número de bagos para o cultivar Muscat Seedless.

Na África do Sul, 'Sultanina' é o mais importante cultivar de uvas sem sementes. É normalmente tratado com $\mathrm{GA}_{3}$ visando a melhoria da qualidade dos bagos (Van der Merwe et al., 1991; Wolf et al., 1991). A época de aplicação do $G A_{3}$ é crítico ao se considerar o desenvolvimento fisiológico dos cachos (Wolf et al., 1991; Wolf \& Loubser, 
1994) realizaram estudos para avaliar o efeito de aplicações tardias e elevadas doses de $\mathrm{GA}_{3}$ sobre os niveis de resíduos deste regulador em bagos com comprimento de $10 \mathrm{~mm}$ até cinco semanas após a colheita. Verificaram que os níveis de ácido giberélico diminuíram sistematicamente nos bagos, ao longo do tempo, a partir do momento que estes apresentavam $10 \mathrm{~mm}$ de comprimento até a pós-colheita. Entretanto, os niveis de $\mathrm{GA}_{3}$ detectados foram mais elevados quando aplicados em altas doses. Outra descoberta de Wolf \& Loubser (1994) foi um retardamento na maturação dos bagos quando $\circ \mathrm{GA}_{3}$ fol aplicado em altas doses. Os autores também constataram que não houve incremento no peso de bagos quando foram efetuadas aplicações tardias de $\mathrm{GA}_{3}$. Contudo, as altas doses e as aplicações tardias de $G \mathrm{~A}_{3}$ resultaram no aparecimento de manchas nos bagos.

Luvisi \& Schrader (1994) realizaram experimentos com 0 cultivar Thompson Seedless, enxertado em dez diferentes porta-enxertos, efetuando, em todas as combinaçōes enxerto/porta-enxerto, três aplicações de $\mathrm{GA}_{3}$ : a primeira de $10 \mathrm{mg} / \mathrm{l}$ no pleno florescimento, seguida de duas outras pulverizações de $50 \mathrm{mg} / \mathrm{l}$ durante a frutificação. Os cachos florais foram podados, deixando-se de seis a oito ombros e as videiras também foram aneladas. Não foram observadas diferenças no tamanho dos bagos e peso dos cachos entre as diferentes combinações enxerto/porta-enxerto.

Jensen et al. (1994) instalaram ensaio na Califórnia para verificar o efeito do ácido giberélico na concentração de $100 \mathrm{mg} / \mathrm{l}$ em diferentes épocas do amadurecimento dos frutos. Os resultados mostraram decréscimo no peso de bagos à medida que a aplicação se distanciava do início da frutificação. Os tratamentos com uma aplicação do ácido no início da frutificação e uma segunda aplicação 
1 ou 2 semanas após, mostraram pesos médios de bagos superiores em relação aos demais tratamentos. Concomitantemente, foi observada a redução no teor de sólidos solúveis e na acidez dos bagos à medida que a segunda aplicação se distanciava do início da frutificação. Os autores concluíram que qualquer programa do uso de $\mathrm{GA}_{3}$ precisa começar com uma aplicação do ácido no início da frutificação, uma vez que neste estádio as respostas à sua aplicação são melhores.

Colapietra et al. (1995) realizaram ensaio com o cultivar de uvas sem sementes Centennial Seedless para verificar o efeito da poda dos cachos e de tratamentos com $\mathrm{GA}_{3}$ em diferentes doses e épocas. Verificaram que a aplicação de $G_{3}$ na dose de 40ppm na frutificação mais a poda dos cachos, produziu maior aumento no peso de cachos $(43 \%)$ e peso de bagos $(48,4 \%$ ). A poda dos cachos durante ou após o florescimento não produziu efeito sobre o peso dos cachos e dos bagos.

É importante ressaltar que o ácido giberélico, além de aumentar o tamanho de bagos, pode também causar efeitos negativos, tais como decréscimo na frutificação, flacidez dos ramos e dos bagos, deterioração, abscisão e retardamento na maturação de bagos póscolheita (Jawanda et al., 1974; Singh et al., 1978). 'Muscat Seedless' é um cultivar especialmente propenso a estes defeitos, de modo que a aplicação de $G_{3}$ neste cultivar é feita pela imersão dos cachos em baixas doses de ácido giberélico (Van der Merwe et al., 1991; Orth, 1990). 


\subsection{Modificaçōes citológicas e fisiológicas na planta com a aplicação do ácido giberélico}

A ação da giberelina tem sido intensivamente estudada em viticultura. Aplicações de $\mathrm{GA}_{3}$ efetuadas a partir do aparecimento da inflorescência até o início da maturação dos frutos visam principalmente o aumento do peso dos bagos e dos cachos, os quais tornam-se medianamente soltos, dispensando o desbaste, além de facilitar o controle de doenças. Como resultado da ação do $G A_{3}$ na planta, ainda são citados o engrossamento dos pedicelos e dos engaços e a diminuição do ciclo da videira, antecipando-se o início da colheita (Pereira \& Oliveira, 1976).

Os mecanismos que promovem a elongação celular, em conseqüência da ação da giberelina ainda não é explicado de modo claro. Entretanto, diversas teorias têm sido aventadas. A giberelina pode induzir a formação de enzimas proteolíticas que liberariam o triptofano. que é um precursor do ácido indolacético, a principal auxina (Van Oberbeek, 1966). Conseqüentemente, o nivel de auxinas aumenta. A giberelina poderia, também, transportar auxinas para seu local de ação em plantas (Kuraishi \& Muir, 1963). Ela poderia induzir a produção de $\alpha$-amilase, que promove a hidrólise do amido, a formação de açúcares, que acarretam na diminuição do potencial osmótico no interior da célula, ocorrendo um influxo de água que tende a dilatá-la, resultando na elongação celular e no aumento do tamanho dos cachos. Motomura \& Ito (1972) observaram que a aplicação de $G_{3}$ promove a translocação de nutrientes para os cachos, sendo esse efeito fundamental para aumentar a frutificação da videira. 
As mudanças fisiológicas que ocorrem por ocasião da aplicação do $\mathrm{GA}_{3}$ estão associadas a aumentos na taxa de divisão celular ou aumento da célula. O pericarpo aumenta com a aplicação de $G A_{3}$, resultante de mudanças na partição de assimilados (Weaver et al., 1969; Little \& Loach, 1975) ou na plasticidade da parede celular dos bagos (Adams, 1975). As enzimas que enfraquecem as paredes da célula seriam induzidas pelo $\mathrm{GA}_{3}$

(Mc Leod \& Millar, 1962).

Fellman et al (1991) sugerem que a aplicação de $G A_{3}$ préantese levam ao desenvolvimento desigual entre o pistilo e o saco embrionário, o desenvolvimento do pistilo é acelerado, o mesmo não acontecendo com o desenvolvimento do saco embrionário, resultando em falha na dupla fertilização e falha no desenvolvimento das sementes. Ocorre, ainda, um grau de desenvolvimento desigual entre o pistilo e o saco embrionário por ocasião da floração precoce, o que resulta no aparecimento de uvas sem sementes.

\subsection{Efeito do anelamento associado ao ácido giberélico em cultivares de uva de mesa}

Weaver et al. (1969) observaram bagos e cachos mais pesados no cultivar Black Corinth como resultado da aplicação de $G A_{3}$ com e sem anelamento.

A aplicação de ácido giberélico, assim como o anelamento e desbaste dos cachos são práticas culturais que afetam a qualidade da uva, apresentando efeitos no número, cor e tamanho dos bagos e compacidade e maturação dos cachos (Weaver, 1976). 
Os resultados conflitantes obtidos por Andris (1981) e Ezzahouani et al. (1985) com o cultivar Ruby Seedless, levaram Harrell \& Williams (1987) a iniciar estudos com os cultivares Thompson Seedless e Ruby Seedless para avaliar a influência do anelamento, do $G A_{3}$ e a combinação destas duas técnicas sobre o peso de bagos, a maturação dos frutos e a produção. Os resultados obtidos para o cultivar Ruby Seedless foram: aumento significativo no peso dos bagos nos tratamentos com aplicação de $G A_{3}$ nos cachos, anelamento e a combinação destes tratamentos. No início da frutificação, os tratamentos levaram a um aumento de $16 \%$ no peso de bagos. 0 peso dos bagos do cultivar Thompson Seedless foi significativamente aumentado por todos os tratamentos com $\mathrm{GA}_{3}$ ou anelamento.

Zabadal (1992) realizou dois experimentos durante três anos para verificar o efeito do anelamento e aplicações de $G A_{3}$ no cultivar Himrod seedless. No primeiro experimento, o número e o peso de bagos e o peso dos cachos mostrou aumento estatisticamente significativo quando as videiras foram submetidas ao desbaste das flores mais anelamento. No segundo experimento, o tratamento que incluia anelamento, desbaste de frutos e aplicação de $G A_{3}$, assim como o tratamento que envolvia o desbaste das flores mais $G A_{3}$ resultou em aumento estatisticamente significativo no peso e número de bagos e peso dos cachos. O desbaste dos frutos isoladamente ou associado ao anelamento aumentou significativamente 0 peso dos bagos e dos cachos, não acontecendo o mesmo com o número de bagos por cacho. Sempre que foi utilizado o anelamento, o peso e número de bagos e o peso dos cachos foi maior que o controle, melhorando, assim, a qualidade dos frutos. 
Pommer et al. (1995) realizaram experimento com o cultivar Maria (IAC 514-6), empregando quatro tratamentos com $G A_{3}$. Todos os tratamentos diferiram estatisticamente entre si e da testemunha para massa, comprimento e largura de cachos e dos bagos. Considerandose a massa média dos cachos, o tratamento incluindo anelamento mais $\mathrm{GA}_{3}$ excedeu em $405 \%$ a testemunha, em $30 \%$ ao tratamento somente com $\mathrm{GA}_{3}$, e em $49 \%$ àqueles das plantas aneladas. Para a mesma característica, o tratamento com $\mathrm{GA}_{3}$ excedeu ao tratamento com anelamento. Cachos tratados com $G_{3}$, ou plantas aneladas, apresentaram valores altamente significativos para as características estudadas em relação à testemunha. Foi ainda verificado que quanto mais próximo dos cachos for feito o anelamento, maior seu efeito.

Antonacci \& Colleta (1996) pulverizaram o cultivar Regina no início do desenvolvimento dos frutos com 2 ou $4 \mathrm{mg}$ de ácido giberélico por litro de água com ou sem anelamento feito após a frutificação. Todos os tratamentos aumentaram os pesos médios de cachos comparados com os controles não tratados. A aplicação de $2 \mathrm{mg}$ de ácido giberélico por litro mais anelamento resultou nos maiores valores de peso médio de cachos. Os tratamentos com ácido giberélico com ou sem anelamento não acarretaram efeitos estatisticamente significativos no conteúdo de açúcar, acidez ou pH. Os mesmos autores realizaram um segundo experimento, aplicando a dose de $2 \mathrm{mg}$ de ácido giberélico por litro no início da frutificação e de $20 \mathrm{mg} /$ /itro no final da frutificação, comparado a somente uma aplicação de $2 \mathrm{mg}$ de ácido giberélico. Concluíram que duas aplicações de ácido giberélico produziram os melhores resultados. 


\section{MATERIAL E MÉTODOS}

\subsection{Cultivar estudado}

Fol utilizada a uva 'Maria' (IAC 514-6), obtida na Seção de Viticultura, do Instituto Agronômico de Campinas, cuja genealogia (Santos Neto, 1984) é a seguinte:

Highland $\quad x$ Golden Queen

$\downarrow$

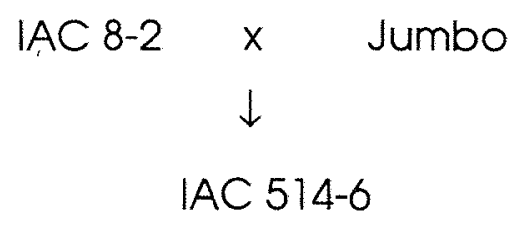

Trata-se de cultivar de uva fina de mesa, vigorosa, com produtividade média de $2,5 \mathrm{~kg} / \mathrm{m}^{2}$ que, nas condições de Jundiaí, SP, completa seu ciclo vegetativo em 150 dias. Pode ser conduzida nos sistemas de espaldeira, latada ou manjedoura, com poda média de 3 a 5 gemas (Terra et al., 1985). Apresenta baixa resistência às moléstias criptogâmicas, principalmente com relação ao oídio, causado pelo 
patógeno Uncinula necator (Schw.) Burril, (Oidium tuckeri Berk.), Galli et al. (1968). Seus cachos são cilíndrico-cônicos, compactos, necessitando do desbaste dos bagos. Os pedicelos prendem firmemente os bagos, proporcionando resistência à degrana. Seus bagos são pequenos, de cor amarelo-esverdeados quando maduros, de forma esferóide, apirenos por estenoespermocarpia, sabor neutro, textura trincante, apresentam resistência ao transporte e à consenvação. No periodo de colheita, com chuvas prolongadas, não racham nem apodrecem, permanecendo em perfeitas condições na planta. (Terra et al., 1985)

\subsection{Generalidades}

O experimento foi realizado no ciclo vegetativo de 1995, em vinhedos comerciais da Chácara Extra-Vitis, de propriedade de Carbonari e Caniato, localizada no Bairro do Poste, Municipio de Jundiai, SP, situado a $23^{\circ} 06^{\prime}$ de latitude sul, $46^{\circ} 55^{\prime}$ de longitude oeste e $715 \mathrm{~m}$ de altitude, em latossolo vermelho-amarelo.

A região, do ponto de vista climático, apresenta-se de acordo com o sistema proposto por Köeppen, classificada como Cfa (Setzer, 1986).

As videiras em estudo estavam com 12 anos de idade e enxertadas sobre o porta-enxerto IAC 766 'Campinas'. Essas videiras estavam plantadas no espaçamento de $2 \times 1,5 \mathrm{~m}$, sendo conduzidas no sistema de espaldeira com 3 fios de arame, com poda em cordão esporonado, deixando-se 3 a 4 gemas por ramo produtivo.

Os tratos culturais, o controle de pragas e moléstias e 0 sistema de adubação foram feitos de acordo com a recomendação de Pires \& Terra (1986). 
Como fonte de giberelina fol usado o Pro-Gibb, produto comercial embalado e comercializado pela Divisão de Produtos Agropecuários da Abbott Laboratórios do Brasil Ltda, em que 10 gramas do produto correspondem a 1 grama de ácido giberélico. Novapal, um policondensado de ácido láurico e amino álcool produzido pela Bayer do Brasil S.A, a 0,1\%, fol empregado como agente surfactante.

A aplicação da solução contendo ácido giberélico, baseou-se na imersão total por 10 segundos das inflorescências ou cachos, no período das 8:00 horas às 10:00 horas da manhã.

As soluções de ácido giberélico na concentração de 200ppm, foram preparadas com água destilada momentos antes da aplicação.

$O$ anelamento no tronco principal foi realizado com incisor de lâmina dupla, com largura de corte de $6,3 \mathrm{~mm}$. Nos ramos do ano, fol feito com incisor tipo alicate, também com lâmina dupla, com largura de $4,7 \mathrm{~mm}$. Nos tratamentos com anelamento nos ramos do ano, foram anelados 3 ramos por planta nas 5 repetições.

A poda das videiras fol realizada em 24/07/95; a aplicação do ácido giberélico e o anelamento nos ramos do ano (diâmetro de $0,95 \mathrm{~cm}$ ) e nos troncos principais (circunferência de $12,5 \mathrm{~cm}$ ) foram realizados em duas épocas distintas, ou seja, no início do florescimento (20\% de flores abertas) em 12/09/95 e 13 dias após o florescimento em 25/09/95. As colheitas foram realizadas em 04/12/95 quando os frutos apresentavam teor de sólidos solúveis de 13,20 Brix, acidez total de $15,2 \mathrm{meq} / \mathrm{g} / \mathrm{l}(\mathrm{NaOH})$ e $\mathrm{pH}$ de 3,1 .

O delineamento estatístico utilizado fol o inteiramente casualizado com doze tratamentos e cinco repetições, sendo cada parcela constituída por 1 planta, totalizando 60 plantas. 
Os tratamentos obedeceram o esquema seguinte:

1- Planta sem anelamento, com cachos imersos na solução de ácido giberélico, no início do florescimento-SACGIF;

2- Planta com anelamento no tronco principal, sem cachos imersos na solução de ácido giberélico no início do florescimento ATSGIF :

3- Planta com anelamento no tronco principal, com cachos imersos na solução de ácido giberélico, no início do florescimento ATCGIF;

4- Planta sem anelamento, com cachos imersos na solução de ácido giberélico, após o florescimento - SACGPF;

5- Planta com anelamento no tronco principal, sem cachos imersos na solução de ácido giberélico, após o florescimento - ATSGPF;

6- Planta com anelamento no tronco principal, com cachos imersos na solução de ácido giberélico, após o florescimento - ATCGPF;

7- Planta com anelamento nos ramos do ano, sem cachos imersos na solução ácido giberélico, no início do florescimento - ARSGIF;

8- Planta com anelamento nos ramos do ano, com cachos imersos na solução de ácido giberélico, no início do florescimento ARCGIF;

9- Planta com anelamento nos ramos do ano, sem cachos imersos na solução de ácido giberélico, após o florescimento - ARSGPF;

10- Planta com anelamento nos ramos do ano, com cachos imersos na solução de ácido giberélico, após o florescimento - ARCGPF;

11- Planta sem anelamento, sem cachos imersos na solução de ácido giberélico, no início do florescimento - SASGIF :

12- Planta sem anelamento, sem cachos imersos na solução de ácido giberélico, após o florescimento - SASGPF; 
Completado o ciclo da cultura, com os frutos perfeitamente sazonados, efetuou-se a colheita dos cachos marcados, em número de 3 por planta, que foram acondicionados em sacos de polietileno, e armazenados em câmara frigorífica a temperatura de $2{ }^{\circ} \mathrm{C}$ com $90 \%$ de umidade relativa, onde permaneceram por duas semanas até a completa avaliação dos dados mensurados: 1 - Peso, largura, e comprimento dos cachos, 2 - Peso, largura e comprimento dos engaços, 3 - Peso, largura, comprimento dos bagos e diâmetro do pedicelo, 4 Número de bagos por cacho, 5 - Peso médio de 30 bagos subamostrados por cacho.

As medidas lineares dos engaços foram tomadas com 0,1 centímetro de precisão em uma régua Trident; as medidas lineares dos bagos foram tomadas com 0,01 centímetro de precisão em um paquímetro MAUB; as medidas de peso dos parâmetros estudados foram determindas com precisão de 0,1 grama em uma balança Mettler PI200N.

Foram realizadas as análises de variâncias dos contrastes ortogonais pelo programa SAS entre médias de tratamentos para as características mensuradas nos bagos, cachos e engaços segundo Gomes (1985). Estas análises foram divididas em duas etapas, a primeira no sentido de se verificar o efeito de época, e a segunda para verificar os efeitos dos tratamentos. 


\section{RESULTADOS E DISCUSSÃO}

As médias dos doze tratamentos efetuados encontram-se na Tabela 1. Verifica-se que os tratamentos-controle apresentaram sempre resultados inferiores àqueles em que foi realizado o anelamento e a aplicação de ácido giberélico.

A fim de verificar primeiramente o efeito da época dos tratamentos, foi realizada, na primeira etapa, a análise de variância de contrastes ortogonais entre médias dos tratamentos para as características de bagos, cachos e engaços, apresentada na Tabela 2. Constata-se que não foram detectados efeitos estatisticamente significativos do anelamento e da aplicação de ácido giberélico entre diferentes épocas para a maioria das características. Baseado nestes resultados, numa segunda ełapa, foram analisados os tratamentos, não considerando os efeitos de épocas de anelamento e/ou aplicação de ácido giberélico.

Estes resultados discordam dos estudos realizados por Winkler (1953) e Pires (1988) e concordam com os estudos de Pires et al. (1987). Winkler (1953) constatou efeito do anelamento em diferentes épocas no cultivar Thompson Seedless, concluindo que o anelamento 
30

deve ser feito logo após a queda das flores inviáveis, seguido do florescimento. Pires et al. (1987) estudou a influência de doses, épocas e número de aplicações de ácido giberélico na uva 'Iracema', não observando diferenças significativas entre as diferentes épocas para as variáveis analisadas. Pires (1988) constatou que as doses de 400 ou 800ppm de ácido giberélico, aplicadas 14 dias após a floração em cachos do cv. Maria promoveu grande aumento no peso dos cachos e dos bagos. 


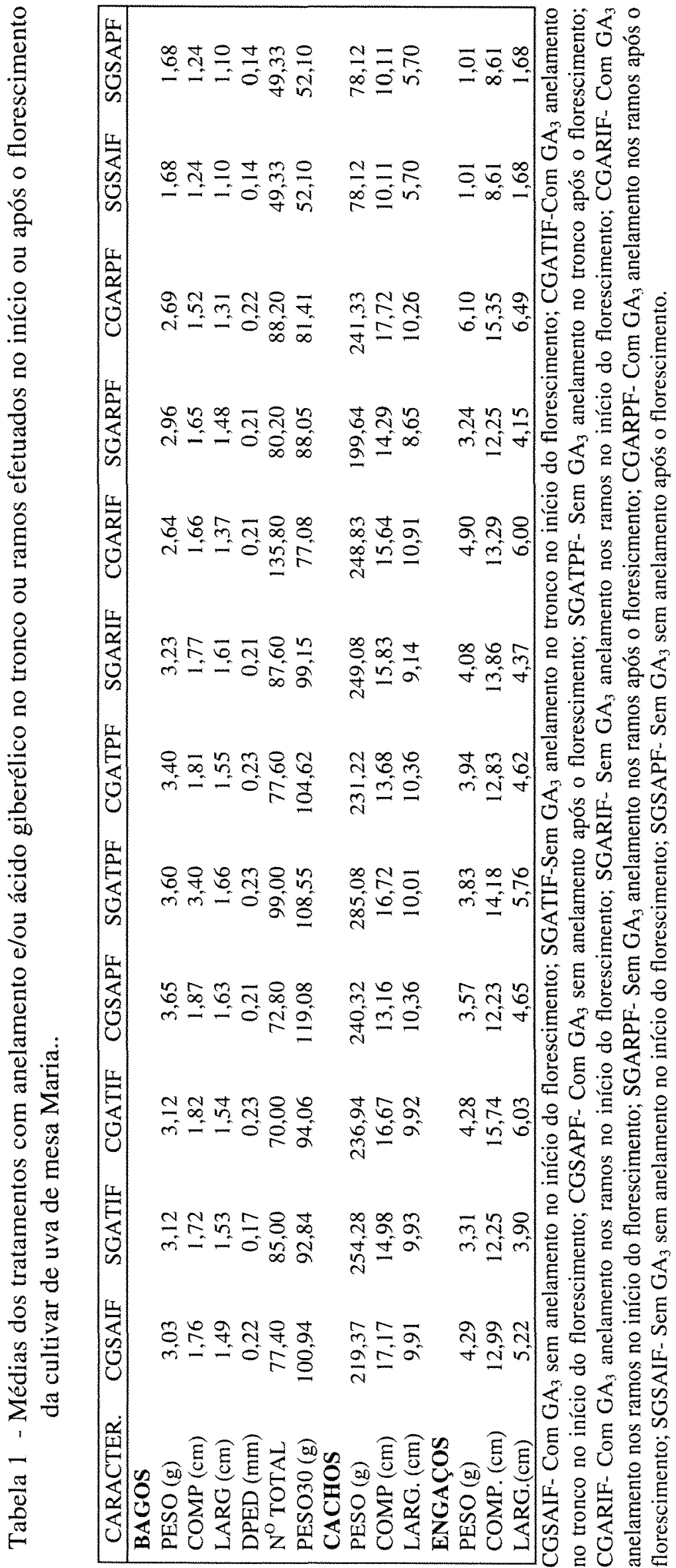


Tabela 2 - Efeito da época do anelamento e/ou da época de aplicação do ácido giberélico $\left(\mathrm{GA}_{3}\right)$ nas características das bagas, dos cachos e dos engaços do cultivar de uva de mesa Maria

\begin{tabular}{|c|c|c|c|c|c|c|}
\hline \multirow[t]{2}{*}{ Característica } & $\begin{array}{l}\text { CGATIF/ } \\
\text { CGATPF }\end{array}$ & $\begin{array}{l}\text { SGATIF/ } \\
\text { SGATPF }\end{array}$ & $\begin{array}{l}\text { CGARIF/ } \\
\text { CGARPF }\end{array}$ & $\begin{array}{l}\text { SGARIF/ } \\
\text { SGARPF }\end{array}$ & $\begin{array}{l}\text { CGSAIF/ } \\
\text { CGSAPF }\end{array}$ & CV\% \\
\hline & \multicolumn{6}{|c|}{ Valores $\mathrm{F}$ dos contrastes entre médias } \\
\hline \multicolumn{7}{|l|}{ Bagos } \\
\hline Peso (g) & 0,56 n.s. & 1,97 n.s. & 0,01 n.s. & 0,61 n.s. & 2,32 n.s. & 18,47 \\
\hline Comprim. $(\mathrm{cm})$ & n.s. & 0,70 n.s. & 1,18 n.s. & 0,95 n.s. & 0,03 n.s. & 12,11 \\
\hline Largura $(\mathrm{cm})$ & n.s. & 1,18 n.s. & 0,26 n.s. & 1,26 n.s. & 0,17 n.s. & 12,27 \\
\hline Diâm.ped (mm) & n.s. & 6,97 n.s. & 0,01 n.s. & 0,01 n.s. & 0,15 n.s. & 16,40 \\
\hline $\mathrm{N}^{\mathrm{o}}$ total & 0,27 n.s. & 0,82 n.s. & $10,61 * *$ & 0,26 n.s. & 3,11 n.s. & 27,83 \\
\hline Peso 30 bagos $(\mathrm{g})$ & 0,76 n.s. & 1,50 n.s. & 0,13 n.s. & 0,84 n.s. & 2,29 n.s. & 20,90 \\
\hline \multicolumn{7}{|l|}{ Cachos } \\
\hline Peso (g) & 0,03 n.s. & 0,78 n.s. & 0,05 n.s. & 2,28 n.s. & 0,02 n.s. & 23,40 \\
\hline Comprim. $(\mathrm{cm})$ & 3,28 n.s. & 1,11 n.s. & 1,79 n.s. & 0,99 n.s. & 3,21 n.s. & 16,43 \\
\hline Largura $(\mathrm{cm})$ & 0,07 n.s. & $0 \quad$ n.s. & 0,18 n.s. & 0,10 n.s. & 0,01 n.s. & 25,82 \\
\hline \multicolumn{7}{|l|}{ Engaços } \\
\hline Peso (g) & 0,16 n.s. & 0,32 n.s. & 1,90 n.s. & 0,92 n.s. & 0,01 n.s. & 36,30 \\
\hline Comprim. $(\mathrm{cm})$ & $5,64 *$ & 2,22 n.s. & 2,82 n.s. & 1,72 n.s. & 0,58 n.s. & 14,96 \\
\hline Largura $(\mathrm{cm})$ & 2,62 n.s. & $4,00 *$ & 0,32 n.s. & 0,06 n.s. & 0,97 n.s. & 29,16 \\
\hline
\end{tabular}

CGATIF - Anelamento no tronco com GA3 no início do florescimento; ATCGPF - Anelamento no tronco com GA3 após o florescimento; CGARIF - Anelamento nos ramos com GA3 no início do florescimento; ARCGPF - Anelamento nos ramos com GA3 após o florescimento; SGARIF Anelamento nos ramos sem GA3 no início do florescimento; ARSGPF - Anelamento nos ramos sem GA3 após o florescimento; CGSAIF - Sem anelamento com GA3 no início do florescimento; SACGPF sem anelamento com GA3 após o florescimento. SGATIF - Anelamento no tronco sem GA3 no início do florescimento. ATSGPF - Anelamento no tronco sem GA3 após o florescimento.

* significativo ao nível de $5 \%$ de probabilidade;

** significativo ao nível de $1 \%$ de probabilidade; n.s. - Contrastes não significativos 
Os valores das médias dos contrastes ortogonais para as diferentes características dos bagos, cachos e engaços estão apresentados na Tabela 3.

Tabela 3 - Valores das médias dos tratamentos que compoõem os contrastes ortogonais para diferentes características dos bagos, cachos e engaços de uva de mesa cultivar Maria.

\begin{tabular}{|lrrrrrr|}
\hline CARACTERÍST. & SGSA & \multicolumn{1}{c}{ SGAT } & SGAR & CGSA & CGAT & CGAR \\
\hline BAGOS & & & & & & \\
PESO (g) & 1,68 & 3,36 & 3,10 & 3,34 & 3,26 & 2,67 \\
COMP. (cm) & 1,24 & 1,78 & 1,65 & 1,82 & 1,81 & 1,59 \\
LARG.(cm) & 1,09 & 1,60 & 1,54 & 1,56 & 1,55 & 1,34 \\
DIÂM..PED. (mm) & 1,40 & 2,00 & 2,00 & 2,10 & 2,20 & 2,10 \\
$\mathrm{~N}^{\mathrm{O}}$ TOTAL & 49,33 & 92,00 & 83,90 & 75,10 & 73,80 & 112,00 \\
PESO 30 (g) & 52,10 & 100,69 & 93,60 & 110,01 & 99,34 & 79,24 \\
CACHOS & & & & & & \\
PESO (g) & 78,12 & 269,68 & 224,36 & 229,85 & 234,08 & 245,08 \\
COMP.(cm) & 10,11 & 15,85 & 15,06 & 15,16 & 15,17 & 16,68 \\
LARG. (cm) & 5,70 & 9,97 & 8,90 & 10,14 & 10,14 & 10,59 \\
ENGAÇOS & & & & & & \\
PESO (g) & 1,02 & 3,57 & 3,67 & 3,93 & 4,11 & 5,51 \\
COMPR. (cm) & 8,61 & 13,28 & 13,06 & 12,61 & 14,29 & 14,32 \\
LARG. (cm) & 1,68 & 4,83 & 4,27 & 4,94 & 5,33 & 6,25 \\
\hline
\end{tabular}

SGSA - sem anelamento sem GA3; SGAT - sem GA3 anelamento no tronco; SGAR - sem GA3

anelamento nos ramos; CGSA - com GA3 sem anelamento; CGAT - com GA3 anelamento no tronco; CGAR - com GA3 anelamento nos ramos

As análises de variância dos contrastes ortogonais encontam-se na Tabela 4. As figuras 1 a 12 ilustram as médias para efeito de análise dos contrastes considerados na segunda etapa.

Nesta análise não foram considerados efeitos de época de anelamento e/ou aplicação de hormônio, uma vez que estes não foram significativos para a quase totalidade das características de bagos, cachos e engaços do cultivar Maria, conforme comentado com relação aos resultados da Tabela 2 . 


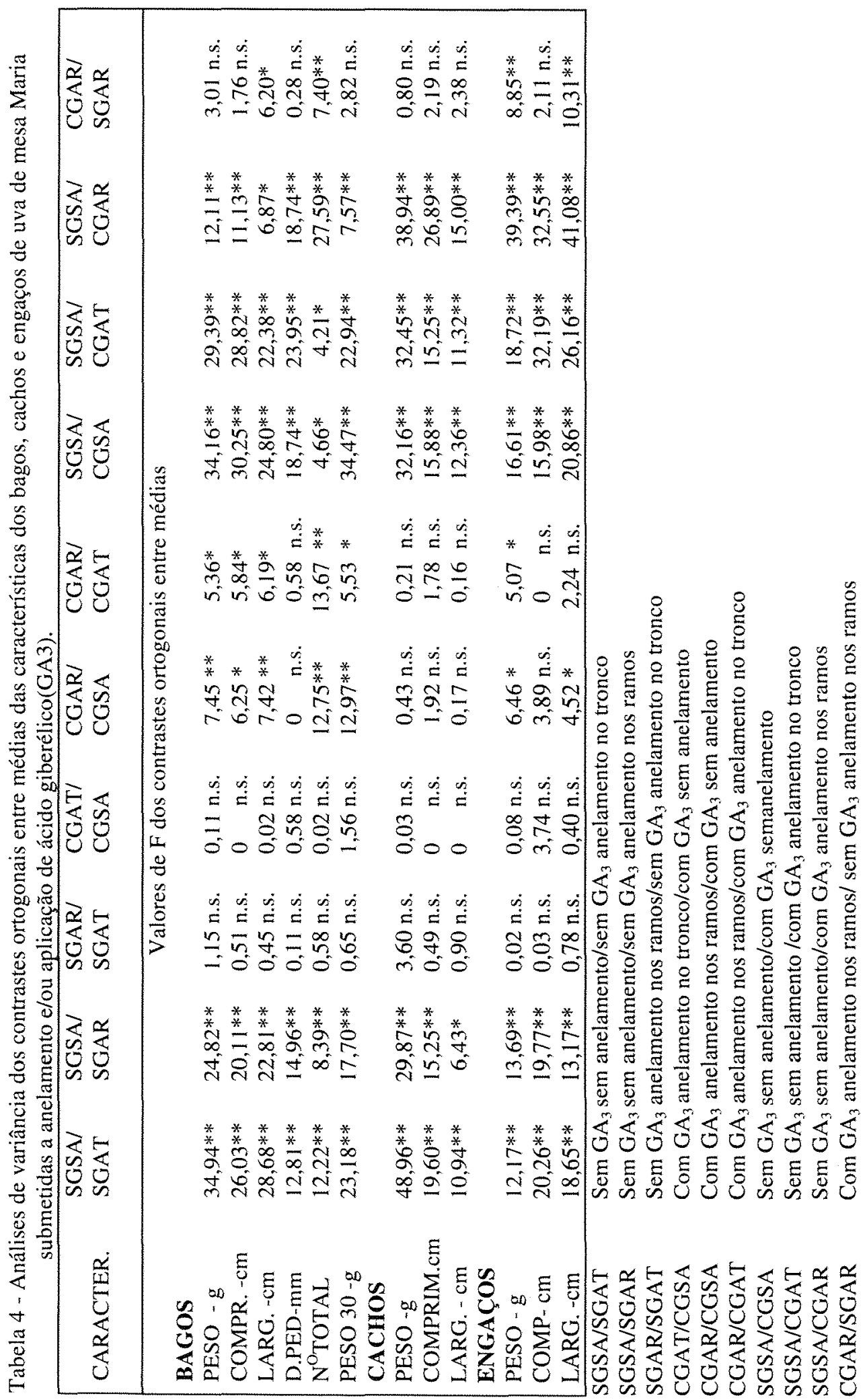


Figra 1- Eeitochanelamento eadicaçäocbácicbgiberélio sctre opesoce begescle wa altiver Mtria

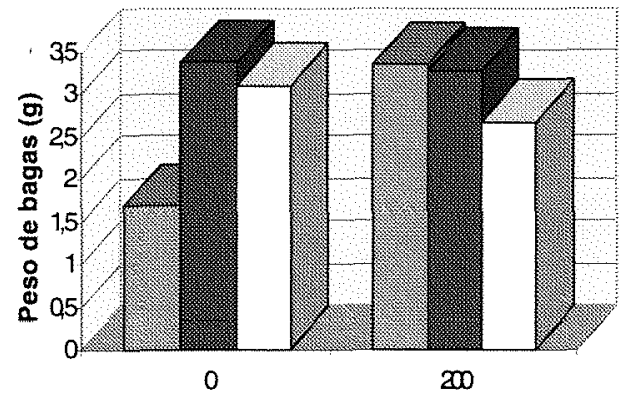

Oncertraçãode Ádicb Clerélico(pp)
Figura 2 - Eeito do anelamento e aplicação do ácido giberélico sobre o comprimento de bagas de uva cultivar Maria

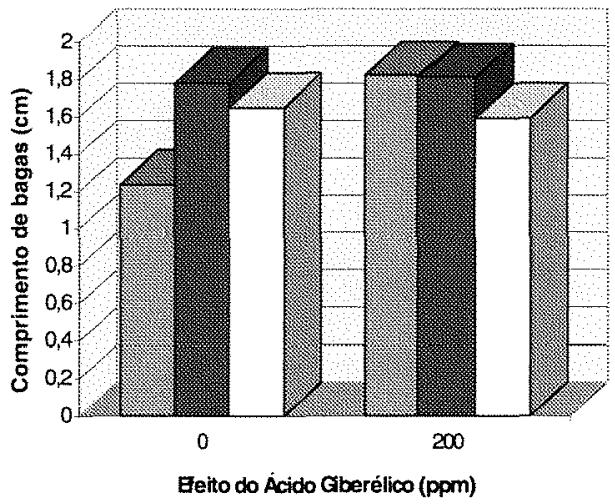

圈SA

Figura 3- Eeito do anelamentoe aplicaçāo do ácido giberélico sotre a largura de begas ce ua cltiver Meria

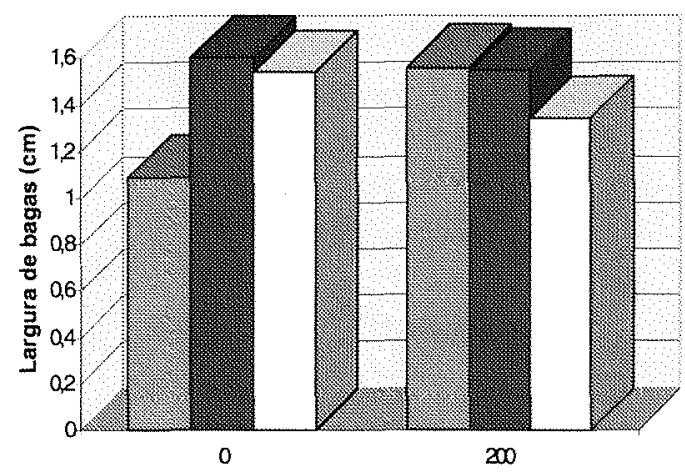

Concentraçä́ de Ácico Gberélioo (pqm)

Figura 5- Beito do anelamento de aplicaçäo do ácicb giberélico sobre o nimero total de bagas ce una cultivar Maria

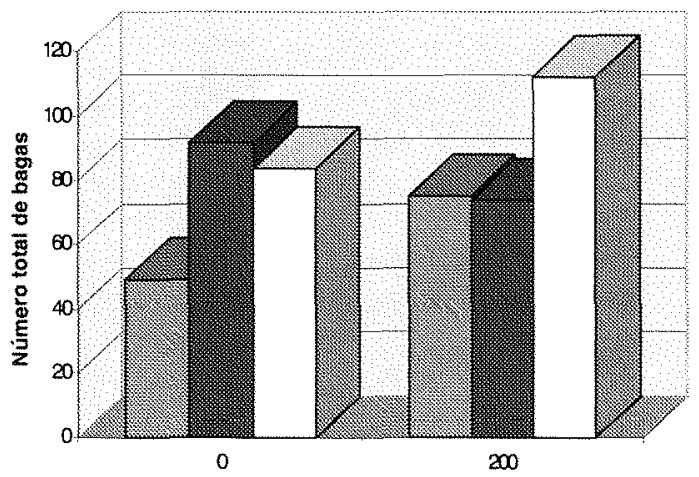

Concentraçăo de Ácido Gberélico (ppm)

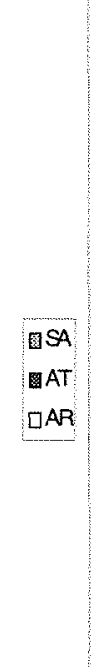

$A T$
Figra 4- Eeitoch arelamerto aplicaçāo dbácicb giberélioo sctre odârnetrodo pedicelo de wa altiver Maria

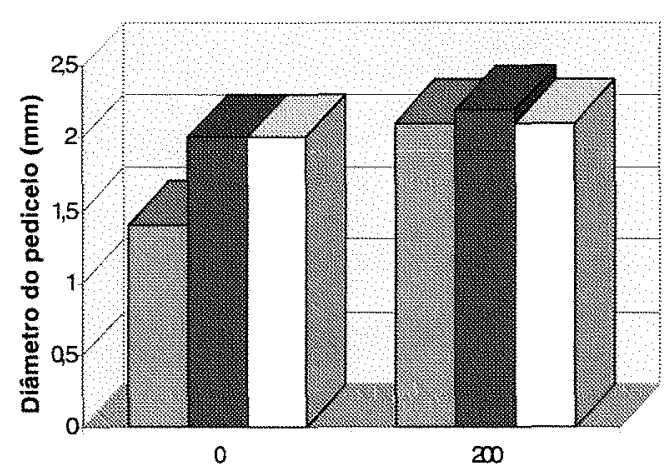

Oancertraçäo de Ádicto Gberélico (ppm)

Figura 6- Eeito do anelamerto e aplicação do ácicb giberélico schre o peso de 30 bagas cle una cattivar Maria

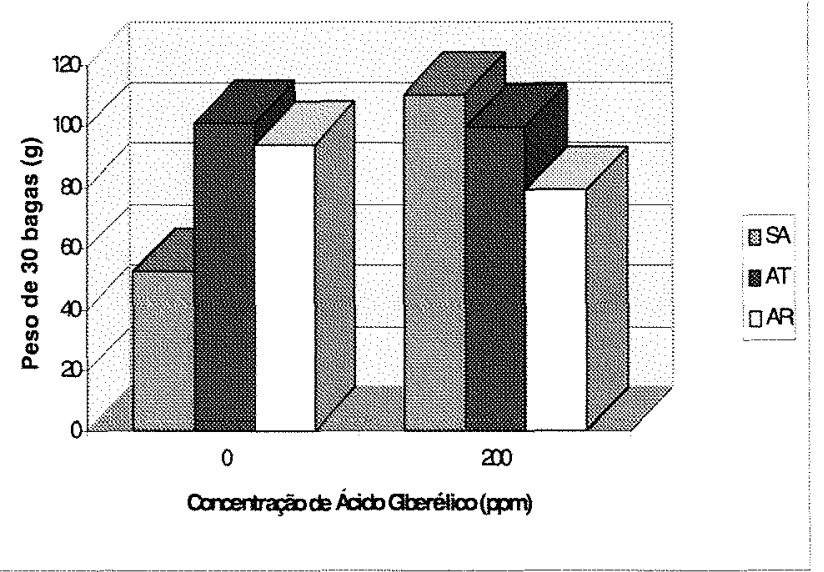


FIGURAS (7-12)

Figra 7- Eeitochanelamentoe aplicação do ádicb giberélio sabre opeso de cadroscte wa cultiver Meria

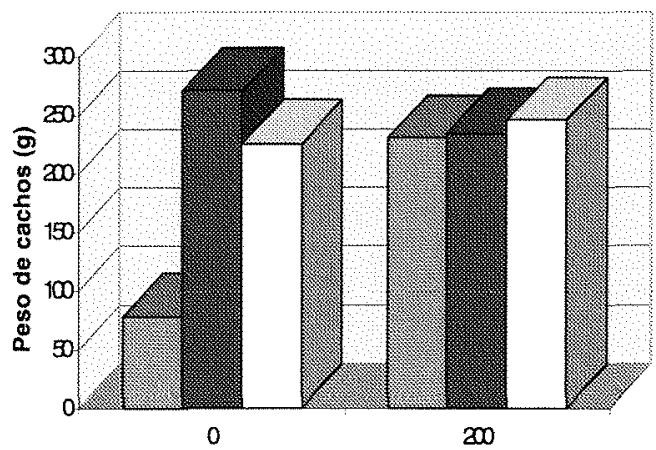

Crcertraçäole Ádich Gcerélico (pm)

Figura 9- Eeitocb anelamertbe aplicação cóacico giberélico sctre a largura de cachos de wa ciltivar Maria

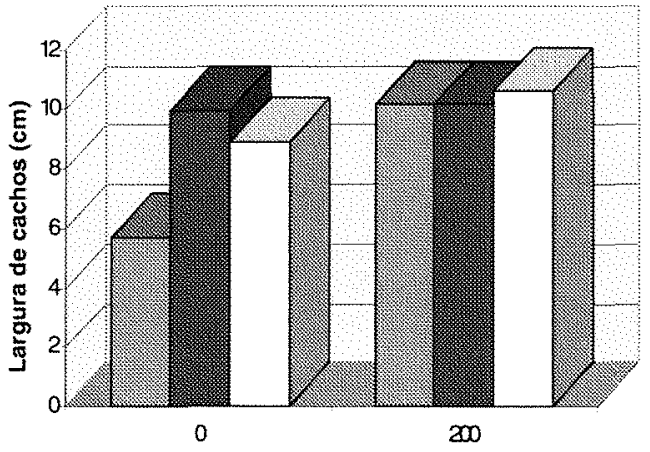

Concertraçäóc Acido Gtberelico (ppm)

Figura 11 - Eeito do anelamento e aplicação do ácido giberélico sctre o comprimerto do engaço de uva altivar Maria

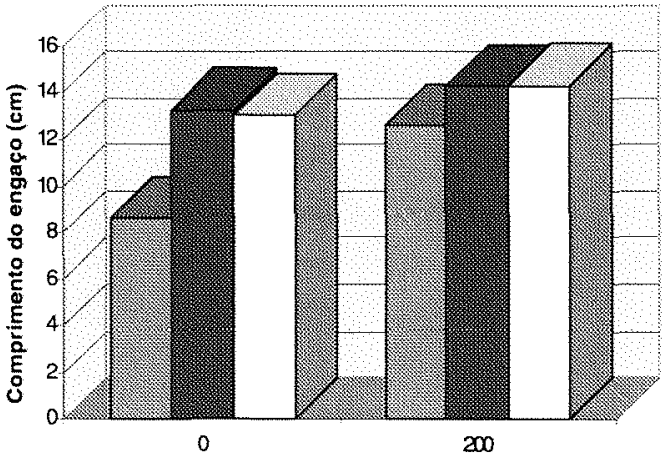

Concentrax̣̆o ce Acico Gberélitio (ppm)
Figura 8- Beito cb anelamento e aplicação cb ácicb giberélico soture o comprimento de cachos de una cuttivar Maria
Figra 10 - Eeito do anelamerto e aplicação do ácicdo giberélico sobre o peso do engago de una cattiver Maria

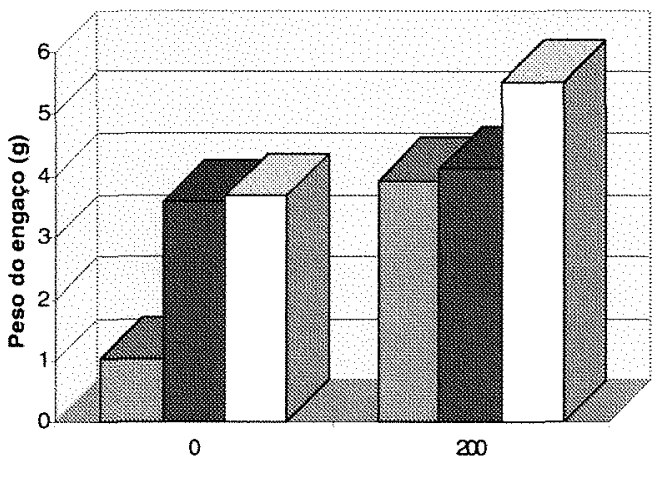

Concentração de Ácido Gberélico (pqm)
Figra 12- Beito do anelamento e aplicação do ácido giberélico sobre a largura do engaço de wa cuttivar Maria

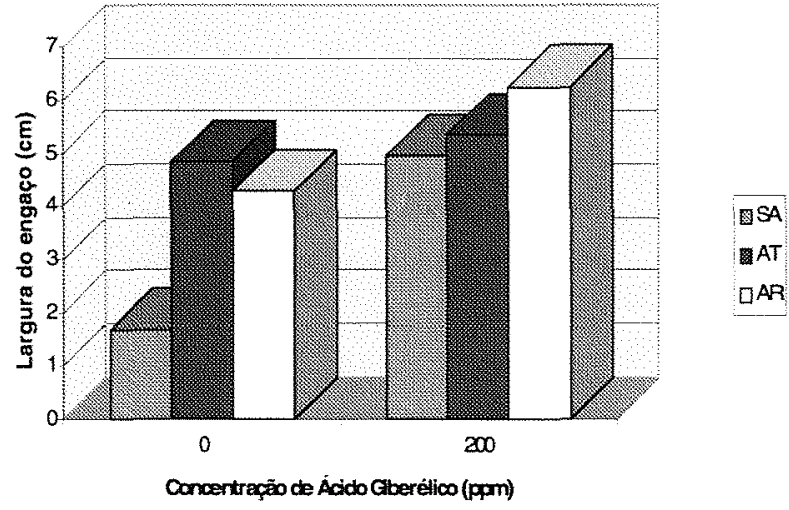

SA - Sem anelamento 
Na tabela 4 observa-se os efeitos significativos do anelamento no tronco (contraste SGSA/SGAD) ou nos ramos (SGSA/SGAR) em relação à plantas não aneladas; da aplicação do ácido giberélico em relação ao controle (SGSA/CGSA); do anelamento no tronco ou nos ramos do ano mais a aplicação do ácido giberélico em relação à plantas controle (SGSA/CGAT e SGSA/CGAR) para todas as características dos bagos, cachos e engaços do cultivar de uva de mesa sem sementes Maria.

Nesta mesma Tabela, verifica-se que em plantas que receberam aplicação do ácido giberélico, o efeito do anelamento nos ramos (contraste CGAR/CGSA), foi significativo ou altamente significativo para peso, comprimento, largura, número total e peso de 30 bagos, e peso e largura dos engaços.

O efeito do anelamento nos ramos, em relação ao anelamento no tronco, em plantas em que foi aplicado o ácido giberélico (contraste CGAR/CGAT) fol significativo ou altamente significativo para peso, comprimento, largura, número total e peso de 30 bagos e peso dos engaços. O anelamento no tronco produziu efeito mais pronunciado que o anelamento nos ramos, para as características de peso, comprimento, largura, peso de 30 bagos e diâmetro do pedicelo. Para as demais características, o anelamento nos ramos foi superior ao no tronco (contraste CGAR/CGAT) (Tabelas 3 e 4).

Verifica-se ainda na tabela 4 que, na ausência de aplicação de ácido giberélico, não foi observado efeito do anelamento no tronco em relação ao anelamento nos ramos (contraste SGAR/SGAT), o que demonstra que a aplicação do ácido giberélico potencializou o efeito do anelamento para certas características. 
Foi observado efeito da aplicação do ácido giberélico em plantas aneladas nos ramos (contraste CGAR/SGAR) para largura. número total de bagos, e peso e largura dos engaços (Tabela 4). Pela magnitude das médias da Tabela 3, pode ser constatado que este efeito fol devido ao anelamento nos ramos no caso da largura dos bagos, e devido ao ácido giberélico para as demais características.

Não foram observados efeitos significativos do anelamento no tronco ou nos ramos do ano na ausência do ácido giberélico (contraste SGAR/SGAT), nem efeito do anelamento no tronco em plantas que receberam aplicação do ácido giberélico (contraste CGAT/CGSA), conforme mostra a Tabela 4.

A Tabela 5 apresenta os incrementos médios nas características dos bagos, cachos e engaços, quando são comparados pares de médias (contrastes ortogonais entre médias) 
Tabela 5 - Incrementos médios percentuais entre os contrastes de médias para as características de bagos, cachos e engaços da uva de mesa cultivar Maria

\begin{tabular}{|c|c|c|c|c|c|c|c|c|}
\hline CARACTERÍSTICAS & $\begin{array}{l}\text { SGSA/ } \\
\text { SGAT }\end{array}$ & $\begin{array}{l}\text { SGSA/ } \\
\text { SGAR }\end{array}$ & $\begin{array}{l}\text { SGAR/ } \\
\text { SGAT }\end{array}$ & $\begin{array}{l}\text { CGAT/ } \\
\text { CGSA }\end{array}$ & $\begin{array}{l}\text { CGAR/ } \\
\text { CGSA }\end{array}$ & $\begin{array}{l}\text { CGAR/ } \\
\text { CGAT }\end{array}$ & $\begin{array}{l}\text { SGSA } \\
\text { CGSA }\end{array}$ & $\begin{array}{l}\text { SGSA } \\
\text { CGAT }\end{array}$ \\
\hline BAGOS - PESO (g) & $100,0^{\mathrm{a}}$ & 84,5 & 8,4 & 2,5 & 25,0 & 22,0 & 98,8 & 94,0 \\
\hline BAGOS - COMPRIM.(cm) & 43,5 & 33,1 & 7,9 & 0,6 & 14,4 & 13,8 & 46,8 & 46,0 \\
\hline BAGOS- LARGURA $(\mathrm{cm})$ & 46,8 & 41,3 & 3,9 & 0,6 & 16,4 & 15,7 & 43,1 & 42,2 \\
\hline BAGOSDIÂM.PEDIC.(mm) & 42,9 & 42,9 & 0,0 & $-4,5$ & 0,0 & 4,8 & 50,0 & 57,1 \\
\hline BAGOS-NOTOTAL & 86,5 & 70,0 & 9,6 & 1,8 & $-32,9$ & $-34,1$ & 52,2 & 49,6 \\
\hline BAGOS-PESO $30(\mathrm{~g})$ & 93,3 & 79,6 & 7,5 & 10,7 & 38,8 & 25,4 & 111,2 & 90,7 \\
\hline CACHOS-PESO $(\mathrm{g})$ & 245,2 & 187,2 & 20,1 & $-1,8$ & $-6,2$ & $-4,5$ & 194,2 & 199,6 \\
\hline CACHOS-COMPRIM. (cm) & 56,8 & 48,9 & 5,2 & 0 & $-9,1$ & $-9,1$ & 50,0 & 50,0 \\
\hline CACHOS-LARGURA $(\mathrm{cm})$ & 74,9 & 56,1 & 12,0 & 0 & $-3,8$ & $-4,2$ & 77,9 & 77,9 \\
\hline ENGAÇOS-PESO $(\mathrm{g})$ & 250,0 & 259,8 & 2,8 & $-4,3^{\mathrm{b}}$ & $-42,3$ & 34,0 & 285,3 & 302,9 \\
\hline ENGAÇOS-COMPRIM $(\mathrm{cm})$. & 54,2 & 51,7 & 1,7 & $-11,8$ & $-11,8$ & $-0,2$ & 46,4 & 66,0 \\
\hline ENGAÇOS-LARGURA (cm) & 187,5 & 154,2 & 13,1 & $-7,3$ & $-21,0$ & $-14,2$ & 194,0 & 217,3 \\
\hline \multirow[t]{2}{*}{ CARACTERÍSTICAS } & SGSA/ & CGSA/ & CGAT/ & CGAR/ & SGAR/ & SGAR/ & CGAR/ & \\
\hline & CGAR & SGAT & SGAT & SGAT & CGSA & CCAT & SGAR & \\
\hline BAGOS - PESO (g) & 58,9 & 0,6 & 3,06 & 25,8 & 7,7 & 4,9 & 16,1 & \\
\hline BAGOS - COMPRIM.(cm) & 28,2 & $-2,2$ & 1,7 & 11,9 & 10,3 & 0.6 & 3,8 & \\
\hline BAGOS- LARGURA (cn) & 22,9 & 2,6 & 3,2 & $-19,4$ & 1,3 & 0,1 & 19,4 & \\
\hline BAGOSDIÂM.PEDIC.(mm) & 50,0 & $-4,8$ & $-9,0$ & $-4,8$ & 5,0 & 10,0 & $-4,8$ & \\
\hline BAGOS-N $\mathrm{N}^{\mathrm{O}} \mathrm{TOTAL}$ & 127,0 & 22,5 & 24,7 & $-17,9$ & $-10,5$ & $-12,0$ & $-25,1$ & \\
\hline BAGOS-PESO $30(\mathrm{~g})$ & 52,1 & $-8,4$ & 1,4 & 27,0 & 17,53 & 6,1 & 18,2 & \\
\hline CACHOS-PESO $(\mathrm{g})$ & 213,7 & 17,3 & 15,2 & 10,0 & 2,4 & 4,3 & $-8,5$ & \\
\hline CACHOS-COMPRIM $(\mathrm{cm})$. & 65,0 & 4,6 & 4,5 & $-5,0$ & 0,7 & 0,7 & $-9,7$ & \\
\hline CACHOS-LARGURA $(\mathrm{cm})$ & 85,8 & 1,7 & 1,7 & $-6,2$ & 13,9 & 13,9 & $-15,9$ & \\
\hline ENGAÇOS-PESO (g) & 440,2 & $-9,1$ & $-13,1$ & $-35,2$ & 7,1 & 12,0 & $-33,4$ & \\
\hline ENGAÇOS-COMPRIM (cm). & 66,3 & 5,3 & $-7,6$ & $-7,3$ & $-3,4$ & 9,4 & $-8,8$ & \\
\hline ENGAÇOS-LARGURA $(\mathrm{cm})$ & 272,0 & 2,2 & $-9,3$ & $-22,9$ & 15,7 & 24,8 & -31.7 & \\
\hline
\end{tabular}

${ }^{1} \mathrm{O}$ primeiro contraste é o de (média inferior. Ex: SGSA $=1,68<3.36=$ SGAT

\begin{tabular}{|c|c|c|}
\hline SGSA/SGAT & $\begin{array}{l}\text { Sem GA3 sem anelamento/ sem GA3 } \\
\text { anelamento tronco }\end{array}$ & SGSA/CGAR \\
\hline SGSA/SGAR & $\begin{array}{l}\text { sem GA3 sem anelamento/ sem GA3 } \\
\text { anelamento nos ramos }\end{array}$ & SGAT/CGSA \\
\hline SGAT/SGAR & $\begin{array}{l}\text { sem GA3 anelamento no tronco/ sem } \\
\text { GA3 anelamento nos ramos }\end{array}$ & SGAT/CGAT \\
\hline CGSA/CGAT & $\begin{array}{l}\text { com } \mathrm{GA} 3 \text { sem anelamento/ com } \mathrm{GA} 3 \\
\text { anelamento no tronco }\end{array}$ & GAR \\
\hline CGSA/CGAR & $\begin{array}{l}\text { com GA3 sem anelamento/ com GA3 } \\
\text { anelamento nos ramos }\end{array}$ & $\mathrm{S}$ \\
\hline CGAT/CGAR & $\begin{array}{l}\text { com GA3 anelamento no tronco/ com } \\
\text { GA3 anelamento nos ramos }\end{array}$ & SGAR/CGAT \\
\hline SGSA/CGSA & $\begin{array}{l}\text { sem GA3 sem anelamento/ com GA3 } \\
\text { sem anelamento }\end{array}$ & SGAR \\
\hline SGSA/CGAT & $\begin{array}{l}\text { sem } \mathrm{GA} 3 \mathrm{sem} \text { anelamento/c } \\
\text { anelamento no tronco }\end{array}$ & \\
\hline
\end{tabular}

sem GA3 sem anelamento/ com GA3 anelamento nos ramos

sem GA3 anelamento no tronco/ com GA3 sem anelamento

sem GA3 anelamento no tronco/ com GA3 anelamento no tronco sem GA3 anelamento no tronco/ com GA3 anelamento nos ramos sem GA3 anelamentonos ramos/ com GA3 sem anelamento

sem GA3 anelamento nos ramos/ com GA3 anelamento no tronco

sem GA3 anelamento nos ramos/ com GA3 anelamento nosramos

a A segunda média do par de médias de um contraste é a superior, acarretando incremento na característica analisada Ex: O contraste SGSAJSGAT significa que o anelamento no tronco aumentou em $100 \%$ o peso dos bagos

${ }^{\mathrm{b}} \mathrm{O}$ sinal negativo indica que, neste caso, a primeira média do contraste é superior, não ocorrendo, portanto, incremento. Ex: O contraste CGAT/CGSA não acarretou incremento no peso dos engaços. 
Na Tabela 5, os maiores incrementos médios percentuais obtidos pelo efeito do anelamento, ou pelo efeito do ácido giberélico, ou pela combinação dos dois fatores foram: variação de $42,9 \%$ para diâmetro do pedicelo a $250 \%$ para peso dos engaços quando o anelamento foi realizado no tronco; variação de $33.1 \%$ para comprimento dos cachos a $259,8 \%$ para peso dos engaços quando o anelamento foi feito nos ramos do ano; variação de $43,1 \%$ para largura dos bagos a $285,3 \%$ para peso dos engaços quando fol aplicado o ácido giberélico: variação de $42,2 \%$ para largura dos bagos a $302,9 \%$ para peso dos engaços quando combinado o anelamento no tronco com o ácido giberélico; e finalmente variação de $22,9 \%$ para largura dos bagos a $440,2 \%$ para peso dos engaços quando combinado o anelamento nos ramos com o ácido giberélico.

$O$ incremento do anelamento no tronco para a característica do peso dos bagos foi de 100\%, enquanto que o anelamento nos ramos aumentou o peso dos bagos em $84,5 \%$ (Tabela 5 e Figura 1). Os comprimentos e as larguras dos bagos do cultivar Maria, por sua vez, aumentaram em $43,5 \%$ e $46,8 \%$, respectivamente, com o anelamento no tronco, e em $33,1 \%$ e $41,3 \%$ com o anelamento nos ramos do ano (Tabela 5, Figuras 2 e 3). Estes efeitos foram altamente significativos para todas estas características, conforme pode ser atestado na Tabela 4 (contrastes SGSA/SGAT e SGSA/SGAR).

Estes incrementos obtidos pelo anelamento no tronco ou nos ramos e/ou aplicação do ácido giberélico acarretaram, portanto, aumentos variáveis no peso, número e dimensões (comprimento e largura) dos bagos, cachos e engaços no cultivar de uva de mesa Maria. 
Os resultados aqui apresentados concordam com os observados por Stewart et al. (1957) que conseguiram bagos $50 \%$ maiores com a aplicação do ácido giberélico nas doses de 10 ou 100ppm no cultivar Thompson Seedless durante o florescimento.

Conforme mostram a Tabela 5 e a Figura 7, o aumento no peso dos cachos quando o anelamento fol realizado no tronco fol de $245,2 \%$ e de $187,2 \%$ quando o anelamento se fêz no ramo, incrementos estes altamente significativos conforme evidenciado na Tabela 4.

Zabadal (1992) constatou aumento significativo no peso dos cachos quando as videiras foram submetidas ao anelamento.

Os dados aqui apresentados são concordantes com essa observação. Peruzzo (1994), também constatou aumentos significativos no peso dos cachos do cultivar Ruby Seedless, em decorrbencia do anelamento nos ramos.

$O$ anelamento efetuado no tronco aumentou 0 comprimento dos cachos em $56,8 \%$ e a largura dos cachos em $74,9 \%$, enquanto que o anelamento feito nos ramos do ano resultou em cachos $48,9 \%$ mais compridos e $56,1 \%$ mais largos (Tabela 5, Figuras 8 e 9). Todos estes efeitos foram altamente significativos ou significativos para estas características (Tabela 4).

A aplicação do ácido giberélico provocou aumento de $98,8 \%$ no peso dos bagos e de $46,8 \%$ e $43,1 \%$ no comprimento e largura dos bagos da uva 'Maria' (contrastes SGSA/CGSA, Tabela 5). Constatouse que estes efeitos obtidos foram altamente significativos (Tabela 4).

Estes resultados concordam com os de Sarooshi (1977), que verificou que pulverizações do ácido giberélico no cultivar Sultana. produziu cachos com bagos graúdos e mais pesados. Kasimatis et al. (1978) também obtiveram aumento no peso dos bagos da videira 
'Thompson Seedless', aplicando o ácido giberélico em pleno florescimento.

Os tratamentos efetuados por Sarooshi (1977) não afetaram significativamente o tamanho dos engaços, resultados estes que diferiram dos obtidos pelo presente trabalho, no qual ocorreu aumentos de $285,3 \%, 46,4 \%$ e $194,0 \%$, respectivamente no peso, comprimento e largura dos engaços com a aplicação do ácido giberélico. Todos estes contrastes foram altamente significativos, segundo a Tabela 4. Lavin (1982), em experimento associando aplicação do ácido giberélico com desbaste de cachos, obteve aumento dos bagos e dos cachos com a aplicação isolada do ácido giberélico. No presente estudo, tanto o peso como o número de bagos aumentou, respectivamente, de $98,8 \%$ e $52,2 \%$, com a aplicação do ácido giberélico (contraste SGSA/CGSA, Tabela 3).

Contudo, estudos prévios realizados por Ezzahouani et al. (1985) não lograram detectar aumentos significativos no peso de bagos com aplicações de ácido giberélico.

Os aumentos do número de bagos, peso e comprimento dos cachos, e peso dos engaços com a aplicação do ácido giberélico em plantas não aneladas foram de 52.2\%, 194,2\%, 50,0\% e 285,3\% respectivamente (Tabela 5, Figuras 5, 7, 8 e 10). O efeito da aplicação do ácido giberélico foi significativo. (contraste SGSA/CGSA, Tabela 4).

Colapietra et al. (1995), trabalhando com o cultivar de uvas sem sementes Centennial Seedless, constataram que a aplicação do ácido giberélico na frutificação mais poda dos cachos produziu maior aumento no peso dos cachos e no peso dos bagos. Os dados aqui encontrados são concordantes com essas observações. 
O efeito complementar do anelamento nos ramos ou no tronco mais a aplicação do ácido giberélico fol evidenciado em expressivos aumentos nas características dos bagos e cachos. $O$ anelamento no tronco com aplicação do ácido giberélico levou a aumentos de $94,0 \%, 46,0 \%, 42,2 \%, 49,6 \%, 199,6 \%, 50 \%$ e $77,9 \%$, respectivamente, para peso, comprimento, largura e número de bagos, peso, comprimento e largura dos cachos em relação a plantas não aneladas no cultivar de uva sem sementes Maria (contraste SGSA/CGAT, Tabela 5, Figuras 1, 2, 3, 5, 7, 8 e 9). $O$ anelamento nos ramos provocou aumentos de $58.9 \%, 28,2 \%, 22,9 \%, 127,0 \%, 213,7 \%, 65 \%$ e $85,8 \%$, respectivamente, para peso, comprimento, largura e número total de bagos, peso, comprimento e largura dos cachos em relação a plantas não aneladas (contraste SGSA/CGAR, Tabela 5, Figuras 1, 2, 3, 5, 7, 8 e 9). Os efeitos para todas as características foram altamente significativos (Tabela 4)

Estes resultados concordam, de modo geral, com os alcançados por Ezzahouani et al. (1985), estudando os cultivares Thompson Seedless e Ruby Seedless. Entretanto, o peso dos bagos, obtido no trabalho de Ezzahouani et al. (1985) para o cultivar Thompson Seedless, ao contrário dos resultados obtidos por esta pesquisa (Tabela 3), não aumentou com os tratamentos. O 'Ruby Seedless' apresentou respostas significativas quanto ao número de bagos por cacho e altamente significativos para o número de bagos $/ \mathrm{cm}$, o qual é considerado um bom indicador de compactação do cacho.

Estes resultados também estão em concordância com os obtidos por Pommer et al. (1995) que, ao realizarem experimento com o cultivar Maria, observaram que o anelamento, a aplicação do ácido giberélico e $\circ$ anelamento mais a aplicação do regulador, 
apresentaram resposta significativa para peso, comprimento e largura de cachos e dos bagos.

Neste trabalho, não foi observado maior aumento nas características dos bagos, cachos e engaços quando o anelamento fol feito associado à aplicação do ácido giberélico. $O$ anelamento feito isoladamente também não diferiu consistentemente da aplicação do ácido giberélico, que significa: visando-se a redução de custos, o produtor pode optar pelo anelamento ou pela aplicação do ácido giberélico realizados isoladamente. Estes resultados diferem dos de Pommer et al. (1995), que constataram efeito do anelamento mais a aplicação do ácido giberélico em relação ao anelamento ou aplicação de ácido giberélico feitos isoladamente. Neste trabalho também não fol constatado efeito superior deste regulador de crescimento em relação ao anelamento, fato este também verificado no trabalho de Pommer et al. (1995). O anelamento nos ramos também não diferiu do anelamento no tronco, sendo recomendado este último, por ser mais fácil de executar, com maior rendimento de mão-de-obra.

Nesta pesquisa, a aplicação do ácido giberélico produziu aumentos de $285,3 \%, 46,4 \%$ e $194,0 \%$ no peso, comprimento e largura dos engaços (contraste SGSA/CGSA); a aplicação do ácido giberélico acompanhada do anelamento no tronco levou a aumentos de $302,0 \%$, $66 \%$ e $217,3 \%$ nas mesmas características dos engaços (contraste SGSA/CGAT) e a aplicação do ácido giberélico mais anelamento nos ramos permitiu o aumento do peso, comprimento e largura dos engaços de $440,2 \%$, 66,3\% e 272,0\%, respectivamente (contraste SGSA/CGAR, Tabela 5, Figuras 10, 11 e 12). Todos estes efeitos foram altamente significativos (Tabela 4). 
Não houve avaliações do aumento ou diminuição do número de cachos e da produção por planta com o anelamento ou com aplicação do ácido giberélico, não permitindo a determinação de estimativas de produtividade por área e o cálculo do aumento da receita bruta obtida pelo produtor para cada hectare de área cultivado. Além disso, Weaver (1955) propōe a verificação do efeito do anelamento precoce, quando o teor de sólidos solúveis é de 5-6\% com o objetivo de apressar a maturação. Este efeito permite a colocação da uva no mercado antecipadamente, permitindo ao produtor alcançar preços melhores Estas informações complementares poderão ser levadas a efeito em trabalhos futuros.

Também poderiam ser introduzidos tratamentos com diversos número de aplicações e concentrações do ácido giberélico em diversas épocas, complementando os tratamentos efetuados neste trabalho.

Entretanto, o aumento no peso dos bagos e dos cachos, bem como nas dimensões dos bagos, cachos e engaços obtidos neste trabalho como resultado de anelamento e/ou aplicação do ácido giberélico, acarretou melhoria no aspecto dos cachos de uva, facilitando sua comercialização.

Os resultados deste trabalho estão de acordo com a literatura que afirma que a aplicação do ácido giberélico, associada ou não ao anelamento constituem-se em tratamentos utilizados para aumentar o tamanho dos bagos. Entretanto, nas Tabelas 4 e 5 e na Figura 5, podem ser observados que o número de bagos aumentou significativamente como conseqüência do anelamento e/ou aplicação do ácido giberélico, ao contrário do reportado em diversos trabalhos que afirmam ocorrer redução no número de bagos em cultivares de 
uvas sem sementes. O aumento no tamanho e número de bagos, por sua vez, redunda em melhoria da qualidade do produto para 0 mercado. Diversos trabalhos conduzidos no Brasil e no exterior sobre estes efeitos têm apresentado respostas diferenciadas a estes tratamentos. Pires et al. (1987) destacam que as diferenças nas respostas destes agentes é dependente principalmente do cultivar e das condições climáticas, determinando, assim, a necessidade de novas pesquisas no sentido de se descobrir a concentração adequada do ácido giberélico e as melhores épocas de aplicação. 


\section{CONCLUSŌES}

Não foram detectados efeitos de época de anelamento e de aplicação de ácido giberélico para a maioria das características dos bagos, cachos e engaços.

Foram constatados aumentos significativos em todas as características quando o anelamento foi realizado no tronco e nos ramos do ano, e quando da aplicação do ácido giberélico, de forma isolada ou combinada com o anelamento.

Ocorreram altos incrementos percentuais em peso, comprimento e largura dos bagos, cachos e engaços como resultado do anelamento no tronco ou nos ramos do ano, com ou sem aplicação do ácido giberélico. 


\section{REFERÊNCIAS BIBLIOGRÁFICAS}

ADAMS, P.A.; MONTAGNE, M.J.; TEPFERD, D.L.; RAYLE, D.L.; IKUMA, K.; KAUFMAN, P.B. Effect of gibberellic acid on the plasticity and elasticity of Avena stem segments. Plant Physiology, v. 56, p. 757-760, 1975.

ANDRIS, H.L. The effect of gibberellin and girdling on Ruby Seedless table grapes. In: PROCEEDINGS OF THE TABLE GRAPE SEMINAR, Fresno, CA, 1981. Anals. University of California Press, 1981. p. 18-20.

ANTONACCI, D.; COLLETA, A. Response of Regina and Regina dei Vigneti table grapes to gibberelin treatments. Rivista di Viticoltura e di Enologia, v.49, n.3, p. 57-64, 1996.

BARCELLOS, F.M. Efeito do ethrel $e$ do ácido giberélico no descompactamento do cacho e outras características do cacho da videira Itália. (Vitis vinifera L.). Pelotas, 1976. 57 p. Dissertação (M.S.) Universidade Estadual de Pelotas. 
BARON, I.; SAHAR, N.; SPIEGEL-ROY, P. The effect of gibberellin on berry size and cluster looseness in seedless varieties of Vitis vinifera. Alon Hanotea, Tel Aviv, 35 (6/7) :385-388,1981.

BEN-TAL, Y. Effects of gibberellin treatments on ripening and berry drop from Thompson Seedless grapes. American Journal of Enology and Viticulture, v. 41, n. 2, p. 142-146, 1990.

COLAPIETRA, M.; TARRICONE, L;; TAGLIENTE, G. Effects of gibberellic acid and cluster thinning on the qualitative caracteristics of table grapes Centennial Seedless. Rivista di Fruticoltura, v. 57, n. 5, p. 65-70, 1995.

COOMBE, B.G. Fruit set and development in seeded grape varieties as affected by defoliation, topping, girdling and other treatments. American Journal of Enology and Viticulture , v. 10, p. 85-100, 1959.

COOMBE, B.G.. Relationship of growth and development to changes in sugars, auxins and gibberelins in fruits of seded and seedless varieties of Vitis vinifera. Plant Physiology, v. 35, p.241-50, 1960.

EL-BANNA, G.I.; WEAVER, R. J. Effect of ethephon and gibberellin on maturation of ungirdled Thompson Seedless grapes. American Journal of Enology and Viticulture , v. 30, n. 1, p. 11-13, 1979.

EZZAHOUANI, A.; LASHEEN, A.M.; WATALI, L. Effects of gibberellic acid and girdling on Thompson Seedless and Ruby Seedless table grapes in Morocco. Hortscience, v. 20, n. 3, p. 393-394, 1985. 
FELLMAN, C..; HOOVER, E.,; ASCHER, P.D.; LUBY, J. Gibberellic acid induced seedlessness in field grown vines of Swenson Red grape. Hortscience, v.26, n.7., p. 873-875, 1991.

FISHER, H. über die blutenbilden substanzen. Flora, v. 94, p. 478-490, 1905.

GALLI, F.; TOKESHAI, H.; CARVALHO, P.C.T.; BALMER.E.; KIMATI, H.; CARDOSO, C.O.N.; SALGADO, C.L. Doenças da videira. In: GALLI, F., coord. Manual de Fitopatologia. São Paulo, Ed. Agronômica Ceres, 1968. p. $456-469$.

GOMES, F.P. Curso de Estatística Experimental. 11.ed. Piracicaba, ESALQ/USP. 1985. 466 p.

GUERRA, M.P.; BARCELLOS, F.M.; KOLLER, O.C.C. Influência do ácido giberélico aplicado em floração e pós-floração sobre as características do cacho da videira Itália. (Vitis vinifera L.) In: CONGRESSO BRASILEIRO DE FRUTICULTURA, 6, Recife, 1981. Anais.Recife, SBF, 1981 p.1278-1286.

HALBROOKS, M.C., CROVETTI, A.J. Gibberelic acid increases berry size, reduces seed traces in Orlando Seedless grape. In: PROCEEDINGS OF THE PLANT GROWTH REGULATOR SOCIETY OF AMERICA, 16th Annual Meeting, Arlington, Virginia, USA, 1989. Anais, Ithaca, New York, USA: Plant Growth Regulator Society of America, 1989, p. 34-39. 
HARRELL, D.C.; WILLIAMS, L.E. The influence of girdling and gibberellic acid application at fruitset on Ruby Seedless and Thompson Seedless grapes. American Journal of Enology and Viticulture, v. 38, n. 2, p. 83$88,1987$.

HIDALGO, L.; \& CANDELA, M.R. . Effectos inducidos por el acido giberelico (BERELEX), em tratamiento unico sobre le "Vitis vinifera". Conais. Vigne et du Vin., v. 5, n. 4, p. 427-460, 1965.

JACOB, H.E.. Girdling grapevines. California Agricultural Extensions Service Circ., S.V., n. 56, p1-18, 1931.

JAWANDA, J.S.; SINGH, R. ; PAL, R.N. Effect of growth regulators on floral bud drop, fruit characteristics and quality of Thompson Seedless grapes (Vitis vinifera L.). Vitis, v. 13, n. 3, p. 215-221, 1974.

JENSEN, F.; SWANSON, F.; LEAVITT, G. Reducing set in Rubby Seedless grapes with gibberellin. California Agriculture , v. 30, n. 5, p. 13, 1976.

JENSEN, F.L.; BIANCHI, M.; MORIYAMA, M. ; KAZARIAN, D. Influence of application timing of gibberellin berry-enlarging treatments on the maturity of Thompson Seedless table grapes. In: INTERNATIONAL SYMPOSIUM ON TABLE GRAPE PRODUCTION, s.l. , California 1994. Annals. California s.l., s.ed., 1994, p. 47-49.

JINDAL, P.C.; SINGH, K.; BAKSHI, J.C. Effect of various concentrations of gibberellic acid applied at various stages of panicle development in Thompson Seedless variety of grape (Vitis vinifera). Haryana Journal Horticultural Science, v. 2, n. 1,2, p. 30-37, 1975. 
KASIMATIS, A.N.; SWANSON, F.H.; VILAS JR., E.P. Effects on bloom applied gibberellic acid on soluble solids and berry weight of Thompson Seedless grapes and on raisin grapes. American Journal of Enology and Viticulture, v. 29, p. 263-266, 1978.

KRIEDEMANN, P.; LENZ, F. The response of vine leaf photosynthesis to shoot tip excision and stem cincturing. Vitis, v. 11, p. 193-197, 1972.

KURAISHI, S.; MUIR, R.M. Diffusible auxin increase in a rosette plant treated with gibberelin. Naturwiss 50, p. 337-338, 1963.

LAVIN, A. Efectos del ácido giberélico (A.G.), descole de racimos y anillado de cargadores sobre producción y algunas características del fruto de vid (Vitis vinifera L. CV. Moscatel Rosada. Agricultura Técnica, v. 42, n. 3, p. 173-176, 1982.

LE CLERC DU SABLON, M. Sur les effets de la decorticacion anulaire (Paris) Acad. des Sci Compt. Rind. v. 140, p. 1553-1555, 1905.

LITTE, C.H.A.; LOACH, K. Effect of gibberellic acid on growth and photosynthesis Abies balsamea. Canadian Journal Botany, v. 53, p. 1905-1910, 1975.

LUVISI, D.A: SCHRADER, P.L. Perfomance of Thompson Seedless and Crimson Seedless tabel grapes on ten rootstocks: a preliminary report.In: INTERNATIONAL SYMPOSIUM ON TABLE GRAPE PRODUCTION, s.I., California 1994. Annals. California s.l., s.ed., 1994, p. 115-119. 
MAKIVIOS, C. Problèmes de lemploi des gibberellines sur les raisins de table. Bulletin De L'O.I.V., v. 544, p.243-252, 1977.

MC LEOD, A.M. : MILLAR, R.A.S. Effects of gibberelic acid on barkley endosperm. Journal Institute Brewing , v. 68, p. 322-332, 1962.

MOTOMURA, Y; ITO, $\mathrm{H}$. Exogenous gibberellin as responsible for the seedless berry development of grapes. II. Role and effects of the prebloom gibberellin application as concerned with the flowering, seedlessness and seedless berry development of Delaware and Campbell early grapes. Tokoku Journal of Agricultural Research, v. 23 , n. 1.p. 15-23, 1972.

MOTOMURA, Y; HORI, Y. Exogenous gibberellin as responsible for the seedless berry development of grapes. VI. Explanation of $G A_{3}$ effects on the induction of seedlessness and seedless berry development varying with cultivars. Tokoku Journal of Agricultural Research, v. 29, n. 3,4, p. $111-119,1978$.

MURNEEK, A.E. Relative carbohydrate and nitrogen concentration in new tissues produced on ranged branches. American Society of Horticultural Science , v. 38, p. 133-136, 1941.

NEWMAN, P.M.; BACKHAUS, R.A.; DOSS, R.P.; SACHS, R.M. Site of in vivo regulation of tree stem elongation by bark banded morphactins. Plant Physiology, v. 40, p. 53-58, 1977. 
ORTH, C.H.F. Effect of spraying or dipping Muscat Seedless with gibberellic acid at different flowering stages on berry set and berry size. Deciduous Fruit Grower, v. 40, n. 11, p.428-432, 1990.

ORTH, C.H.F. Effect of spraying or dipping with gibberellic acid on bud fertility of Muscat seedless.Deciduous Fruit Grower, v. 40, n. 8, p. 289292, $1990 a$

PENTEADO, J.G.; LAWER, P.; ABRAMIDES, E.; PEREIRA, F.M. Efeitos do ácido giberélico em uvas Niagara. In: CONGRESSO BRASILEIRO DE FRUTICULTURA, 3, Rio de Janeiro, RJ, 1975. Anais. Rio de Janeiro, R.U. Soc. Brasil. Frutic. , 1975, v.2, p. 603-608.

PEREIRA, F.M. Estudo da giberelina sobre a videira Niagara Rosada (Vitis labrusca L. - Vitis vinifera L. ).Piracicaba, 1972 134p. Tese (Doutorado) Escola Superior de Agricultura "Luiz de Queiroz", Universidade de São Paulo.

PEREIRA, F.M.: OLIVEIRA, J.C. Ação da giberelina sobre cachos de cV. de videira Patrícia. Científica 4, p. 175-180, 1976.

PERUZZO, E.L. Anelamento dos ramos em variedades de uvas de mesa. Agropecuária całarinense, v. 7, n. 4, p. 21-23, 1994.

PIRES, E.J.P. Efeitos do ácido giberélico nas características dos cachos e das bagas em uva cultivar Maria (IAC 514-6). Piracicaba, 1988.73p. Dissertação (M.S.) - Escola Superior de Agricultura "Luiz de Queiroz", Universidade de São Paulo. 
PIRES, E.J.P.; FAHL, J.I.; TERRA, M.M.; PASSOS, I.R.S.; CARELLI, M.L.C.; RIBEIRO, I.J.A. Efeitos do ácido giberélico nas características morfológicas de cachos de videira IAC 457-11 Iracema. In: SIMPÓsIO LATINO-AMERICANO DE ENOLOGIA E VITICULTURA, 1, Garibaldi, Bento Gonçalves, 1987. Anais. Bento Gonçalves: Associação Brasileira dos Técnicos em Viticultura e Enologia, 1987. p. 196-198.

PIRES, E.P. ; TERRA, M. M. Uvas: é fácil cultivar. São Paulo: Editora Três, 1986. 32 D. (Manuais Práticos de Vida).

POMMER, C.V.; TERRA, M.M.; PIRES, E.I.P.; PICININ, A.H.; PASSOS, R.S. Efeito do anelamento na maturação de uvas com semente. Revista Brasileira de Fruticultura, v. 13, n..3 p. 147-150, p. 1991.

POMMER, C.V.; TERRA, M.M.; PIRES, E.J.P.; PICININ, A.H.; PASSOS, I.R.S. Influência do anelamento e do ácido giberélico em características do cultivar apireno de uvas Maria. Bragantia, v. 54, n. 1, p. 151-159, 1995.

PRAT, C.; SCHAULIS, N.J. Gibberellin induced parthenocarpy on grapes. Proc. American Society of Horticultural Science, v. 77, p. 322-330, 1961.

SANTOS NETO, J.R.A. Apirenia na videira. Belo Horizonte, UVALE S.A., 1984.

SAROOSHI, R.A. Some effects of girdling, gibberellic acid sprays, bunch thinning and timing on the Sultana. Australian Journal of Experimental Agriculture and Animal Husbandry, v. 17, n. 87, p. 700-704, 1977. 
SETZER, J. Atlas Climático e Ecológico do Estado de São Paulo. São Paulo, Instituto Geológico e Geográfico, 1986. 61 p.

SHARMA, J.P.; SINGH, L.; RATHORE, S.V.S. Fruit thinning and stimulatou effects of gibberellic acid on grapes. (Vitis vinifera L.) variety Perlette. Progressive Horticulture, v. 6, n. 4, p. 51-56, 1975.

SHULMAN, Y.; NIR, G.; BAZAK, H.; LAVEE, S. Grapevine girdling by morphactin in oil. Hortscience, v. 21, n. 4, p. 999-1000, 1986.

SINGH, K.; WEAVER, R.J.; JOHNSON, J.O. Effect of applications of gibberellic acid on berry size, shatter, and texture of Thompson Seedless grapes. American of Journal Enology and Viticulture, v. 29, n. 4, p. 258$262,1978$.

STEWART, W.S.; HALSEY, D.D.; CHING, F.T. Effects of potassium salt of gibberellic acid on fruit growth of Thompson Seedless grapes. American Society of Horticultural Science , v. 72, p. 165-169, 1957.

TERRA,M.M.; PIRES,E.J.P.; PASSOS.I.R.S. Uvas IAC sem sementes. Florianópolis, Sociedade Brasileira de Fruticultura, 1985. v.4 n. 3, p. 1618.(Boletim Informativo)

VAN DER MERWE, G.G.; GELDENHUYS, P.D; BOTES, W.S. Guidelines for the preparation of table grape cultivars for Export. Beilville, Republic of South Africa: Unifruco Ltd., 1991, 88p.

VAN OBERBEEK, J. Plant hormones and regulators. Science, v. 152, p. 721-731, 1966. 
WEAVER, R.J. Grape growing. New York: John Willey \& Sons, 1976. $371 p$.

WEAVER, R.J. Relation of time of girdling to ripening to fruit of Red Malaga and Ribier grapes. Proceedings of American Society of Horticultural Science . , v. 65, p.183-186, 1955.

WEAVER, R.J.; MC CUNE, S.B. Girdling: its relation to carbohydrate nutrition and development of Thompson Seedless, Red Malaga and Ribier grapes. Hilgardia, v. 28, p. 421-456, 1959.

WEAVER, R.J.; MC CUNE, S.B. Response of certain varieties of Vitis vinifera to gibberellin. Hilgardia, v. 28, p. 297-350, 1959a.

WEAVER, R.J.; MC CUNE, S.B.; HALE, C.R. Effect of plant regulators on set and berry development in certain seeded and seedless varieties of Vitis vinifera. Vitis, v. 3, n. 4, p. 84-96, 1962.

WEAVER, R.J.; OLMO, H.P. Response of certain varieties of Vitis vinifera grapes to gibberelic acid. In: ANNUAL MEETING OF American Society of Horticultural Science, 54:48 California, 1957.

WEAVER, R.J.; SHINDY, W.; KLIEWER, $M$. Growth regulator induced movement of photosynthetic products into fruits of Black Corinth grapes. Plant Physiology., v. 44, p. 183-188, 1969.

WINKLER, A.J. Producing table grapes of better quality. Blue Anchor v.30, n. 1, p. 28-31, 1953. 
WINKLER, A. J. ; WILLIAMS, W.O. Effect of seed development on the growth of grapes. Proceedings of American Society of Horticultural Science, $V$. 33, p. 430-443, 1963.

WINKLER, A.J.; COOK, J.A.; KLIEWER, W.M.; LIDER, L.A. General Viticulture. Berkeley. University of California Press, 1974. 710p.

WOLF, E.E.H.; LOUBSER, T. Gibberellic acid levels and quality effects of gibberellic acid in treated Sultanina grapes in: INTERNATIONAL SYMPOSIUM ON TABLE GRAPE PRODUCTION, s.l. , 1994. Annals. s.l., s.ed., 1994, p. 54-57.

WOLF, E.E.H.; VAN DEN MERWE; G.G.; ORTH, C.H.F. Optimal gibberellic acid concentrations for the production of high quality Sultanina in the Orange River area. Deciduous Fruit Grower, v. 41, p. 337-340, 1991.

WOLF, E.E.H.; VILJOEN, J.A.; NIEUWENHUYS, A.; LOUBSER, J.T. The effect of Forchchlorfenuron on bunch quality in table grapes. In: INTERNATIONAL SYMPOSIUM ON TABLE GRAPE PRODUCTION, s.l. 1994. Annals. s.l., s.ed., 1994, p.50-53.

ZABADAL, T.J.. Response of 'Himrod' grapevines to cane girdling. Hortscience, v. 27, n. 9, p. 975-976, 1992. 